Title: Quantification of Air Leakage Paths: A Comparison of Airflow and Acoustic Measurements

Authors: Benedikt Kölsch ${ }^{1}$ (corresponding author)

Iain S. Walker, $\mathrm{PhD}^{2}$

Björn Schiricke, $\mathrm{PhD}^{3}$

William W. Delp, $\mathrm{PhD}^{2}$

Bernhard Hoffschmidt, $\mathrm{PhD}^{3}$

Affiliations: 1. Institute of Solar Research

German Aerospace Center (DLR)

Karl-Heinz-Beckurts-Str. 13

52428 Jülich, Germany

Email: benedikt.koelsch@dlr.de

Phone: +4922036012707

Fax: +49 22036014170

2. Building Technology and Urban Systems Division

Lawrence Berkeley National Laboratory

1 Cyclotron Road

Berkeley, CA 94720, USA

3. Institute of Solar Research

German Aerospace Center (DLR)

Linder Höhe

51147 Cologne, Germany 


\title{
Quantification of Air Leakage Paths in Buildings: A Comparison of Airflow and Acoustic Measurements
}

\begin{abstract}
Today, the fan pressurization method is the most frequently used method to evaluate a buildings' airtightness. However, the localization and quantification of leaks remain difficult. In this paper, an acoustic method is introduced to estimate the leakage size of single leaks.

Acoustic and airflow measurements were conducted and compared in laboratory tests within the same boundary conditions. This work aims to investigate if various leak sizes can be predicted using acoustic measurement methods. The test apparatus consists of two chambers, separated by a test wall. This wall represents a single characteristic air leakage path. Various types of wall structures with different slit geometries, wall thicknesses, and insulation materials were investigated. The acoustic measurements were performed with a sound source placed in one chamber and ultrasonic microphones located in both chambers. These results were compared to measured airflows through the test wall to provide estimates of uncertainty in the acoustic approach, which indicate a linear trend. Finally, these laboratory measurements were compared to the same measurements at a real office building. Although the acoustic measurement uncertainty is still significant (greater than $+/-50 \%$ ), the acoustic method has the potential to give an order of magnitude of single leak sizes.
\end{abstract}

\section{Keywords}

Airtightness, Acoustic Measurements, Fan Pressurization, Leakage Paths, Building Envelope, Infiltration 


\section{INTRODUCTION}

According to the International Energy Agency [1], buildings are nowadays responsible for almost a third of the global final energy consumption and account for an equally large share of global $\mathrm{CO} 2$ emissions. The airflow through a building envelope is estimated to account for 30 to $50 \%$ of the building's heating and cooling energy [2] and is, therefore, in addition to thermal transmittance, one of the significant sources for heat losses [3]. Thus, the knowledge of unintended infiltration in buildings is crucial. The most frequently used technique to evaluate a building's airtightness and compare them among each other is the fan pressurization method (known as "blower-door test"). The fan pressurization method is already explained in many international standards like ASTM E779 [4], DIN EN ISO 9972 [5], or CAN/CGSB 149.10 [6]. This measurement method serves the purpose of measuring airtightness to meet requirements to fulfill specific energy performance standards, comparing relative airtightness of different buildings among each other, or determining the reduction of air permeability after refurbishments. In order to reduce air leakage in existing buildings, it is necessary to identify leak locations and prioritize sealing of more substantial leaks. Additionally, the knowledge of leak locations can improve estimates of infiltration airflows [7].

The fan pressurization method only gives the overall leakage rate of one room or building. Quantification and identification of single leaks are challenging, time-consuming, and depend heavily on the respective operator's experience. Leak locations may be identified using, e.g., smoke sticks or anemometers in conjunction with a fan pressurization measurement [8], infrared thermography $[9,10]$, or tracer gases [11,12]. However, smoke sticks and anemometers require a pressure difference to detect leaks. The use of infrared thermography requires, in addition to a pressure difference (at least $10 \mathrm{~Pa}$ [13]), a temperature gradient across the building envelope (at least $5{ }^{\circ} \mathrm{C}$, better $10^{\circ} \mathrm{C}[14]$ ).

The objective of this paper is to investigate the potential for supplementary acoustic methods to identify and quantify single leaks in the building envelope. The acoustic testing removes the need to move large quantities of air through the building envelope because the tests can be performed under naturally occurring 
low or no-flow conditions. These leakage estimates can then be combined with pressure estimates to determine building envelope air flows.

One possible acoustic approach has already been suggested in the ASTM E1186 [8] standard, based on the work done by Keast et al. $[15,16]$. Among other methods like building pressurization and tracer gas detection, this standard recommends the use of sound detection, which is still rarely applied in buildings. Locating leaks by sound detection has been further investigated in laboratory environments $[17,18]$ and real buildings $[19,20]$ using microphone arrays and beamforming. Some related work has been done to quantify [21] and detect [22] holes in pipes with compressed air. Oldham et al. [23] modeled the acoustic and airflow performance of ventilation apertures.

Several other studies examined the sound transmission losses through the building envelope in both laboratory [24-27] and field testing [28-30] to quantify leakage sizes with some success. In addition to the range of audible sound, Graham [31] considered infrasonic impedance measurements for leakage determination, whereas other authors focused on ultrasonic frequencies for localizing [32-34] and quantification $[35,36]$ of air leakages in buildings. Ultrasonic frequencies have the advantage of being above the human auditory threshold of hearing, which may not disturb inhabitants in buildings during measurement. Additionally, ultrasonic wavelengths are in the same order of magnitude as potential leak sizes.

This study aims to examine the magnitude of leakage airflow using a multi-frequency approach in a laboratory test apparatus and the application of this technique in real office buildings. Here, the focus was clearly on quantifying airflows rather than on the detection and location of leaks in building envelopes using sound. In the first part, various wall structures of single leaks are investigated in a laboratory test apparatus, where a comparison between fan pressurization measurements and acoustic measurements has been performed under controlled laboratory conditions (Section 2). In the second part, similar measurements have been performed in a real office building to investigate this method's applicability in field testing (Section 3).

This work is part of ongoing research activities to make remote sensing techniques applicable to thermal 
energy analyses in buildings [37,38]. The overall goal is to develop a toolbox of measurement and analysis methods to determine the thermal properties of building envelopes quickly and accurately. Thus, single buildings or whole districts may be examined in a short period of time to obtain crucial information for the development of renovation strategies or loads of energy networks.

\section{LABORATORY EXPERIMENTAL SETUP}

In this paper, two experimental setups are introduced to compare acoustic measurement procedures with conventional airflow measurements. The first laboratory experiment used a laboratory test box with wellcontrolled artificial leaks of known dimensions and is further described in the following. The second setup is introduced in Section 3.

\subsection{Methodology}

\subsubsection{Laboratory Test Box}

In the first experimental test setup, a wooden test box was constructed, which is shown in Figure 1. The box is made of medium-density fiberboard (MDF) and has a total length of $2.5 \mathrm{~m}$ and a height and depth of $0.6 \mathrm{~m}$. It consists of two chambers with a length of one chamber of $1.1 \mathrm{~m}$. The chambers are separated from each other with a test section, where different leaks could be inserted. Artificial walls were constructed that incorporated leaks of various geometries and were installed in the test section of the apparatus. These two separated chambers ensure a controlled environment on both sides of these artificial walls. For all measurements, the box was closed and air sealed with a lid on top. 


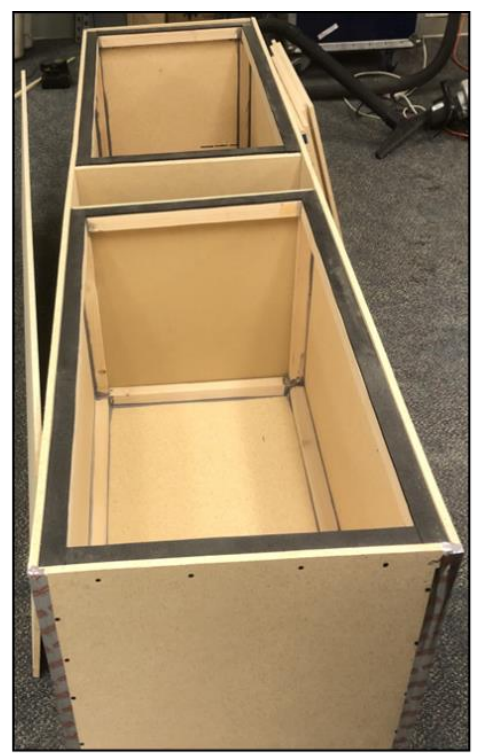

a)

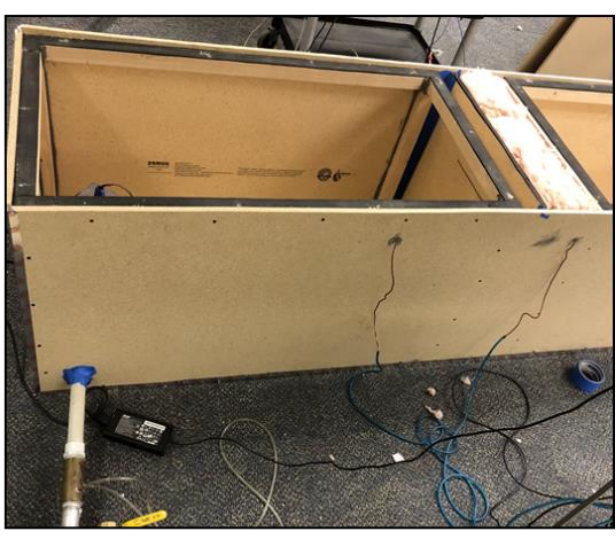

b)

Figure 1: Laboratory test box top view (a) and side view (b)

\subsubsection{Artificial Wall Leaks}

In this first experiment, 43 different configurations of wall leaks have been studied to simulate realistic leakage scenarios for individual leaks on a model scale. The following parameters have been modified between measurements:

- The number of walls: a single wooden wall with a slit in the upper part of the wall or two walls with slits and an air gap between them (Figure $2 \mathrm{a}$ ) and b)). The slit has a length of $180 \mathrm{~mm}$.

- Different distances between the double-wall constructions: 100 and $150 \mathrm{~mm}$ (Figure $2 \mathrm{~b}$ ) and c)). These distances are in the magnitude of typical wall thicknesses.

- Measurements with and without insulating material (glass wool) in between two walls (Figure $2 \mathrm{~d})$ ).

- Connection of the slits at a double wall with a channel (Figure $2 \mathrm{e})$ ).

- Non-parallel leakage paths, where the slit is in one wall at the top and in the other at the bottom. Here, measurements have been performed with and without a channel between the slits (Figure $2 \mathrm{f}$ ) and $\mathrm{g})$ ). 
- Variation of the slit height: 5, 1, 0.4, $0.25 \mathrm{~mm}$ (Figure $2 \mathrm{~h}$ )).

- Blank wall panels without openings for reference purposes.

38 of the total 43 investigated configurations were walls with deliberate openings (shown in Figure 2), and 5 configurations are different types of walls with no openings for reference purposes.

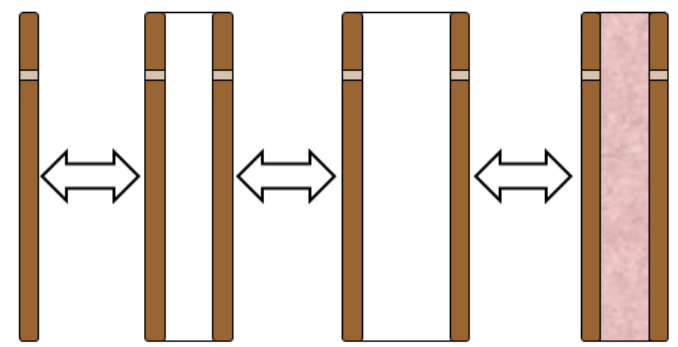

a)

b)

c)

d)

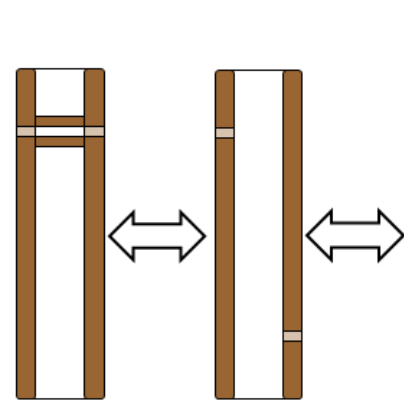

e) f)

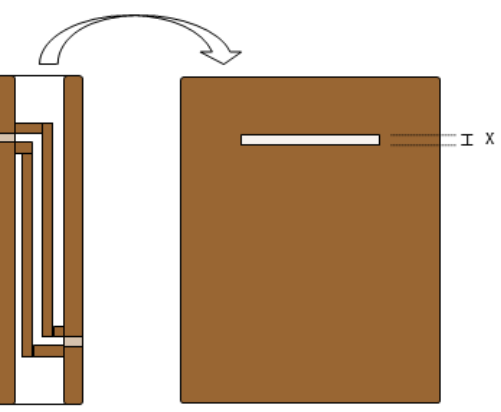

h)

Figure 2: Schematic illustration of configurations and investigated parameters for the 38 artificial wall leaks

\subsubsection{Airflow and Pressure Difference Measurements}

To characterize the test wall leakage, multipoint air leakage tests were performed, similar to the ASTM E779 [4] or DIN EN ISO 9972 [5] standard fan pressurization methods for whole buildings or single rooms.

The blower was connected to one of the two chambers and is shown in Figure 3 a). This pressurized chamber was sealed, and the second chamber was open to ambient conditions. The airflow of this blower was controlled with a manual valve and a blower speed controller. In this experiment, only pressurization and no depressurized tests were performed.

The airflow was measured with a venturi airflow meter installed between the blower and box and is shown 
in Figure 3 b). The venturi airflow meter is schematically illustrated in Figure $3 \mathrm{c}$ ), and the respective airflow can be calculated from the static pressure drop across the convergent section. This correlation is described in Equation 1, where $\mathrm{A}_{1}$ and $\mathrm{A}_{2}$ are the cross-sectional areas at the positions where the pressure measurements were taken, and $\rho$ is the density of air [39]. The positions of the pressure measurement taps [1] and [2] are shown in Figure 3 (b) and (c).

$$
Q=A_{1} \sqrt{\frac{2}{\rho\left(\left(\frac{A_{1}}{A_{2}}\right)^{2}-1\right)}} \cdot \sqrt{\Delta P_{1-2}}
$$

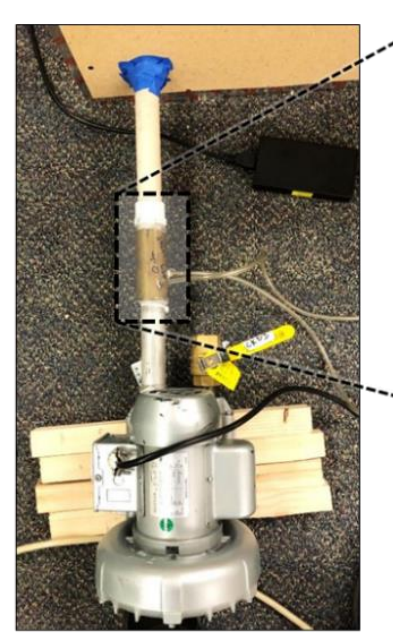

a)

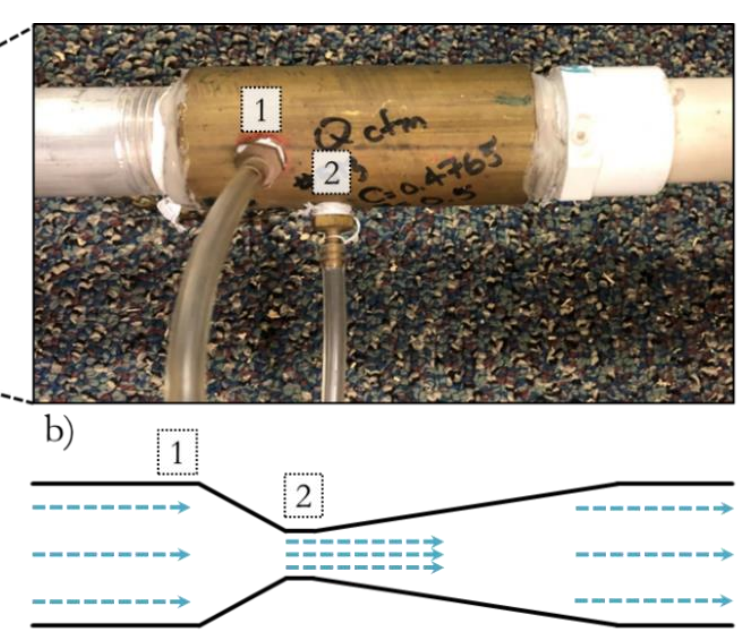

c)

Figure 3: Blower with manual valve (a), Venturi airflow meter with pressure taps (b), and schematic illustration of the Venturi airflow meter (c)

The pressure in the pressurized chamber was measured using a flush-wall pressure tap on the chamber's inner wall. Copper tubing was used to connect the pressure tap location to a differential pressure gauge. Due to the open second chamber to ambient conditions, the pressure difference between both chambers can easily be determined. A second pressure measurement location was inside the double-wall structures (cf. Figure 2 b) to g)) to monitor the pressure difference inside the wall structure as well. With the measurement of pressure difference across the test walls and the airflow through the walls, the pressure exponent $n$ and flow coefficient $C$ of the power-law formulation can be obtained for each leak configuration using a least- 
squares fit to the pressure-flow relationship. We chose the power law formulation because it has been shown to be a good model for airflow in building leaks at the leak dimensions, pressure differences and airflows typical of building envelopes [40] and that were used in this study. Equation 2 shows the correlation between airflow and pressure difference using the power law.

$$
Q=C \cdot \Delta P^{n}
$$

Here, $C\left(\mathrm{~m}^{3} /\left(\mathrm{h} \cdot \mathrm{Pa}^{\mathrm{n}}\right)\right)$ is the flow coefficient, which can be a measure of the overall leak size and $n$ is the

pressure exponent, which describes how leakage changes with pressure difference [41]. This pressure exponent is generally limited to values between 0.5 and 1.0. An exponent of 0.5 is the extreme case of turbulent flow through an orifice where frictional forces can be neglected. An exponent of 1.0 corresponds to leaks with low Reynolds numbers, dominant frictional losses, and, therefore, laminar flows (e.g., long thin cracks) [40]. In many cases, the pressure exponent was found to be in the vicinity of $2 / 3$ in buildings [42]. The acoustic testing presented here is intended to estimate the $C$ and $n$ values for Equation 2.

The temperatures in both chambers were roughly the same $\left( \pm 0.4^{\circ} \mathrm{C}\right)$ during the measurements; therefore, a temperature correction of the airflow through the flowmeter, which is required in ASTM E779 [4] and DIN EN 12114 [43], was not necessary.

\subsubsection{Acoustic Measurements}

The acoustic measurements in the laboratory setup were performed with a speaker placed together with one microphone in one chamber and another microphone in the other chamber. For these measurements, both chambers were sealed to the ambient conditions. All measurements were taken at zero pressure difference and zero airflows. The only intended sound source was the speaker in one of the two chambers. The speaker is an omnidirectional ultrasonic dynamic speaker with an even frequency range of $1-120 \mathrm{kHz}$, and the acoustic transducers are 0.25 -inch condenser microphones with an even frequency response and a recommended frequency range of $0.004-100 \mathrm{kHz}$. The signal which was sent by the speaker was a white noise signal, which enables an analysis of a broad frequency range. In the measurements for this study, the experiments used frequencies between 1 and $40 \mathrm{kHz}$. According to the Nyquist-Shannon sampling theorem 
[44], the sampling frequency of the analog-digital converter should be higher than twice the maximum analyzed signal frequency. Thus, the data acquisition has been performed with a USB wide dynamic range signal analyzer with a sampling frequency of $216 \mathrm{kHz}$ per channel and a resolution of $24 \mathrm{bits}$. An interface between the data logger and measurement computer, as well as the signal generation, was implemented in Python.

The relationship between the signal which is emitted in one chamber and the signal received in the other chamber can be described using the frequency-dependent coherence function $C_{x y}(f)$. The coherence function is a measure of the linear dependency between two discrete time signals $x[n]$ and $y[n]$. It describes the fraction of an output signal from an input signal at a specific frequency. This can be characterized by the following Equation:

$$
C_{x y}(f)=\frac{\left|G_{x y}(f)\right|^{2}}{G_{x x}(f) \cdot G_{y y}(f)}
$$

The coherence is calculated by dividing the squared magnitude of the cross-spectral density $G_{x y}(f)$ between $\mathrm{x}[\mathrm{n}]$ and $\mathrm{y}[\mathrm{n}]$ with the product of the auto-spectral density of signals $\mathrm{x}[\mathrm{n}], G_{x x}(f)$, and $\mathrm{y}[\mathrm{n}], G_{y y}(f)$. This function is always between 1 and 0 , with a value at 1 , indicating a perfect correlation and at 0 a total independence between both signals at a specific frequency $[45,46]$. This paper intends to examine our ability to use the coherence function to estimate the size of building envelope leaks.

\subsection{RESULTS AND DISCUSSION OF LABORATORY MEASUREMENTS}

\subsubsection{Airflow-Pressure Difference Measurements}

For each of the 38 investigated leak configurations, multiple airflow and pressure difference measurements were performed to get a full pressure-flow characteristic for each leak. Figure 4 shows an example of measurement for four selected leak configurations. In the example, a double-wall construction with a $100 \mathrm{~mm}$ distance between both walls, no insulation between these walls, and a connecting canal between 
both parallel slits is shown (cf. Figure 2 e)). The solid lines show the power-law fit to Equation 2 to the measured data (dots). The measured data in this Figure include measurement uncertainties (standard deviation) in airflow and pressure difference, but for the majority of these values the error bars are smaller than the size of the displayed dots. The airflow through the largest slit with a cross-sectional area of $9.0 \mathrm{~cm}^{2}$ (blue) is, as might be expected, the largest. Much smaller is the airflow through slits with a cross-sectional area of 0.7 (green) and $0.4 \mathrm{~cm}^{2}$ (magenta), but even at these small flows, a distinction between both leaks

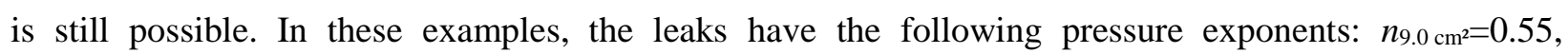
$n_{1.8 \mathrm{~cm}^{2}}=0.64, n_{0.7 \mathrm{~cm}^{2}}=0.71$, and $n_{0.4 \mathrm{~cm}^{2}}=0.76$.

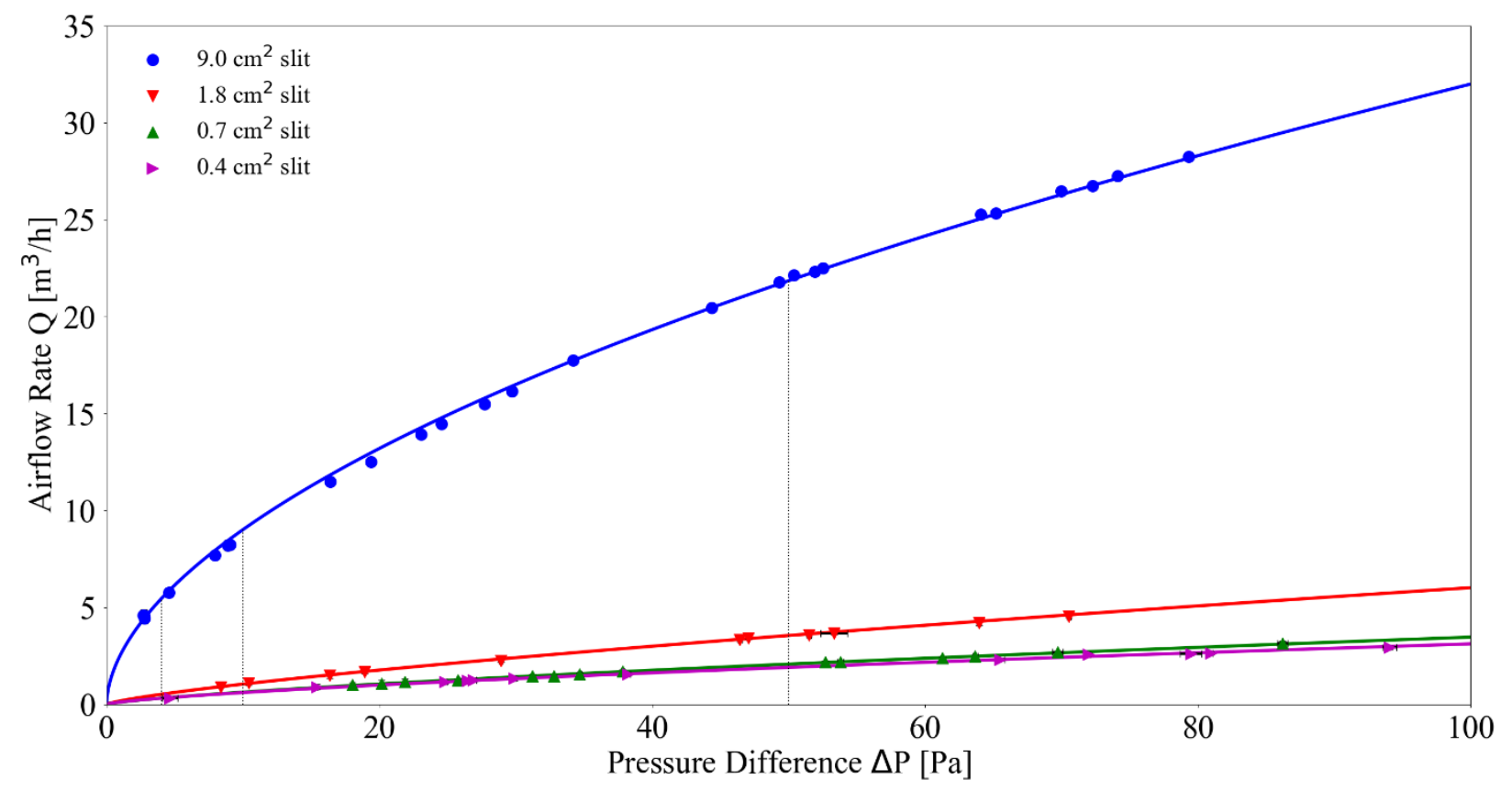

Figure 4: Airflow-pressure measurements of laboratory test apparatus and power low fit for a doublewall construction with $100 \mathrm{~mm}$ distance between the walls, no insulation, and straight connection between the slits for four different slit sizes on a linear scale, including measurement uncertainties

The three black vertical dotted lines indicate the predicted airflows through these leaks at 50, 10, and $4 \mathrm{~Pa}$ pressure difference. $50 \mathrm{~Pa}$ pressure difference is a frequently used value for comparing blower door measurements of real buildings for compliance with building regulations [5], whereas a $10 \mathrm{~Pa}$ pressure difference is used in the Canadian CGSB 149.10 standard [6] to calculate, for instance, the equivalent 
leakage area. At $4 \mathrm{~Pa}$ pressure difference or less, natural infiltration usually occurs in buildings, which is an essential metric in indoor air quality applications [47] and building energy simulations [48]. Additionally, $4 \mathrm{~Pa}$ is also the reference pressure in French blower door guidelines [49]. This is also the reference pressure most often used when converting to equivalent leakage area (e.g., in the ASTM test method).

\subsubsection{Acoustic Measurements}

To reduce the impact of sound transmitted through the wall structure, the impact of background noise and to focus more on the sound transmitted through the openings, the mean coherence value of a wall with no slits was subtracted from the mean value of the same wall with a specific slit for each of the acoustic measurements. This characteristic was determined for each different wall structures (e.g., single or double walls).

The coherence function was calculated for all 38 investigated leak configurations. An example of the measured coherence function (with no airflow) is shown in Figure 5, for the same leak configuration shown previously in Figure 4. Figure 5 also includes the coherence function for the double-wall with no slits (100 $\mathrm{mm}$ distance between the walls and no insulation material between the walls) as the black bottom line. This line shows how sound is transmitted through the wall, even though the wall has no deliberate airflow paths. 


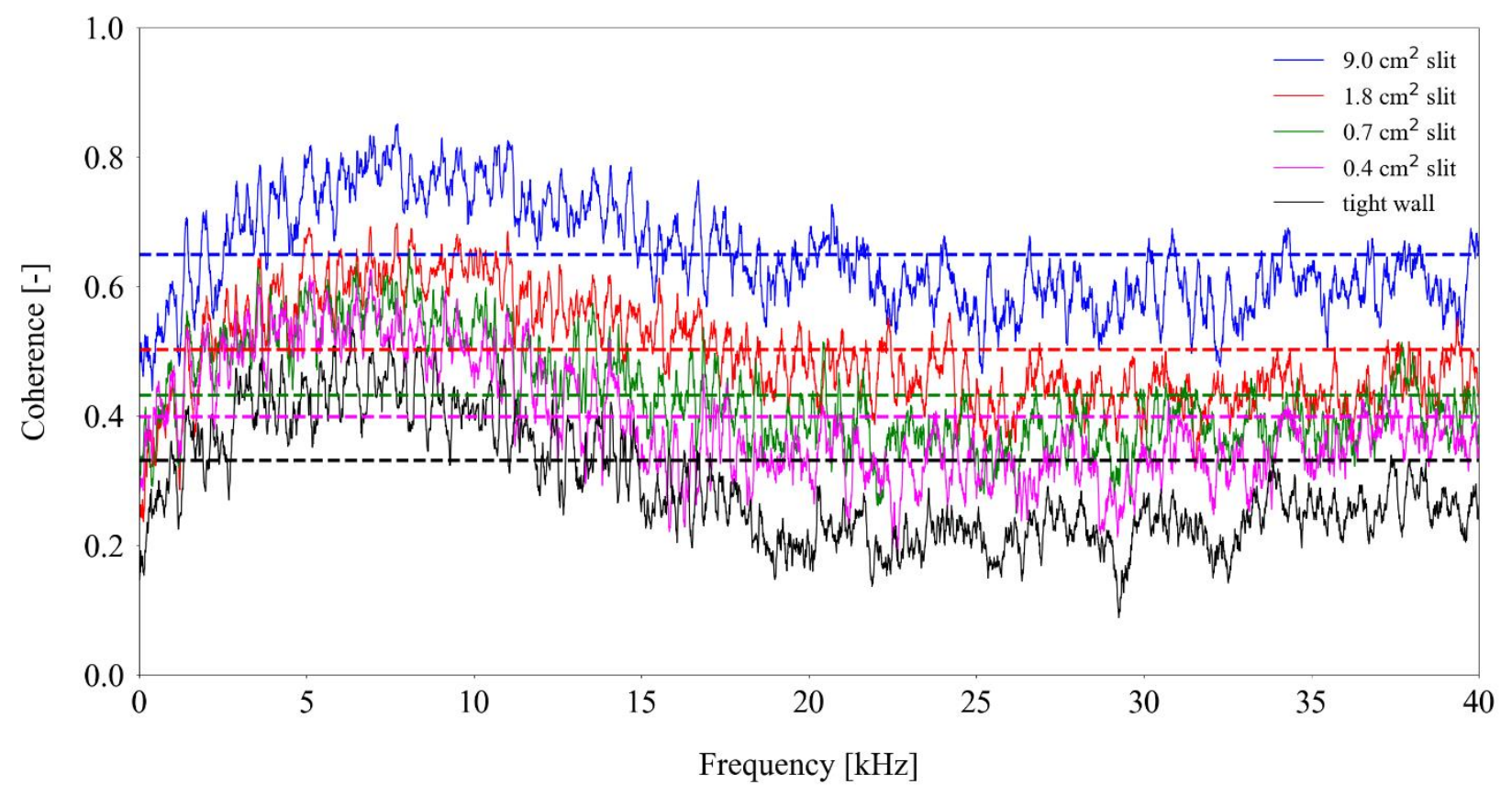

Figure 5: Coherence functions for a double-wall construction with a $100 \mathrm{~mm}$ distance between the walls, no insulation and a connection between the slits for four different slit sizes, and a tight double-wall, with dashed lines indicating the mean values

The dotted horizontal lines in Figure 5 indicate the mean value of the coherence functions over the whole considered frequency spectrum of the leak configurations with the same color. This value increases with increasing slit size.

Figure 6 shows the differences between the coherence of a slit size with a height of $1 \mathrm{~mm}$ (cross-sectional area: $1.8 \mathrm{~cm}^{2}$ ) and an airtight wall for four different wall configurations. The following leak configurations are displayed (cf. Figure 2 a)-d)):

- One wall,

- Two walls with a $100 \mathrm{~mm}$ distance,

- Two walls with a $150 \mathrm{~mm}$ distance,

- Two walls with a $100 \mathrm{~mm}$ distance and additional insulation in between. 
Even though the slit size is the same, the mean magnitudes, as well as the frequency responses, are different for each of these different leak configurations.
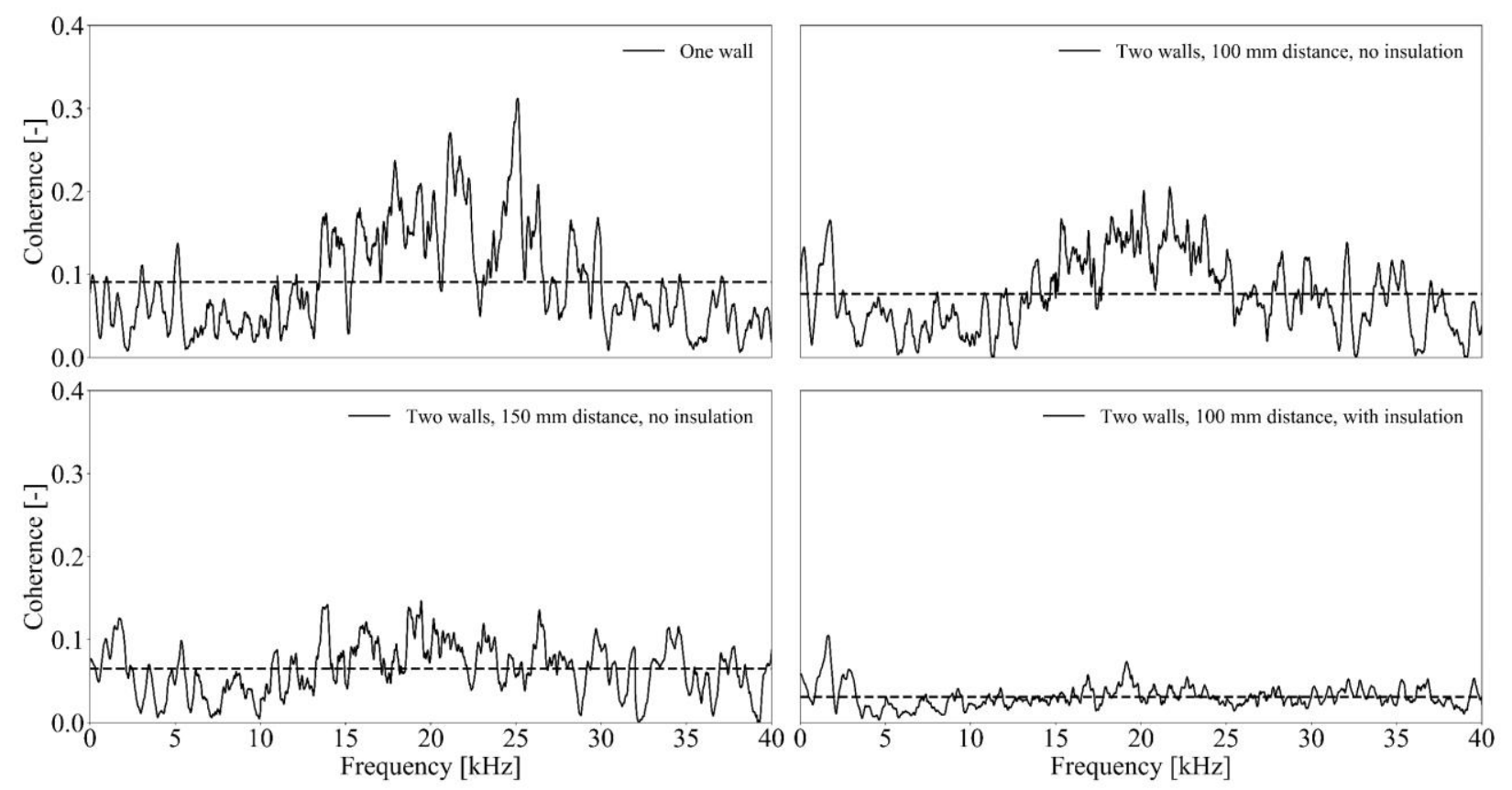

Figure 6: Differences between the coherences of four different wall configurations and the coherence of the same tight wall constructions for the largest slit size of a cross-sectional area of $1.8 \mathrm{~cm}^{2}$, with dashed lines indicating the mean values

The top left configuration with only one wall separating the two chambers has the highest mean magnitude of all four displayed configurations, with its highest peak at around $25 \mathrm{kHz}$. The largest frequency responses are between around 15 and $30 \mathrm{kHz}$, which is still visible at the double-wall construction with a $100 \mathrm{~mm}$ distance between them. However, this second displayed configuration has a lower mean magnitude compared to the single wall construction. Furthermore, the shape of the frequency response is similar for both double wall constructions without insulation between 30 and $40 \mathrm{kHz}$. The last configuration with insulation material between both walls has the lowest mean magnitude of the coherence differences. The insulation material seems to attenuate the frequency components over the whole considered frequency range. Here, no single distinct frequency is visible. These results indicate that there is the potential to identify types of leaks from their sonic signature, which will have to be further investigated in future work. 
In Figures 7-9, the differences between the mean coherence functions of walls with artificial leaks and the same airtight wall constructions are plotted against the respective airflow rates of the same constructions at 50 (red), 10 (grey), and $4 \mathrm{~Pa}$ (green) pressure difference. The airflow rates at these pressure values are extracted from the airflow measurements (as an example illustrated in Figure 4) by interpolation along the fitted curves.

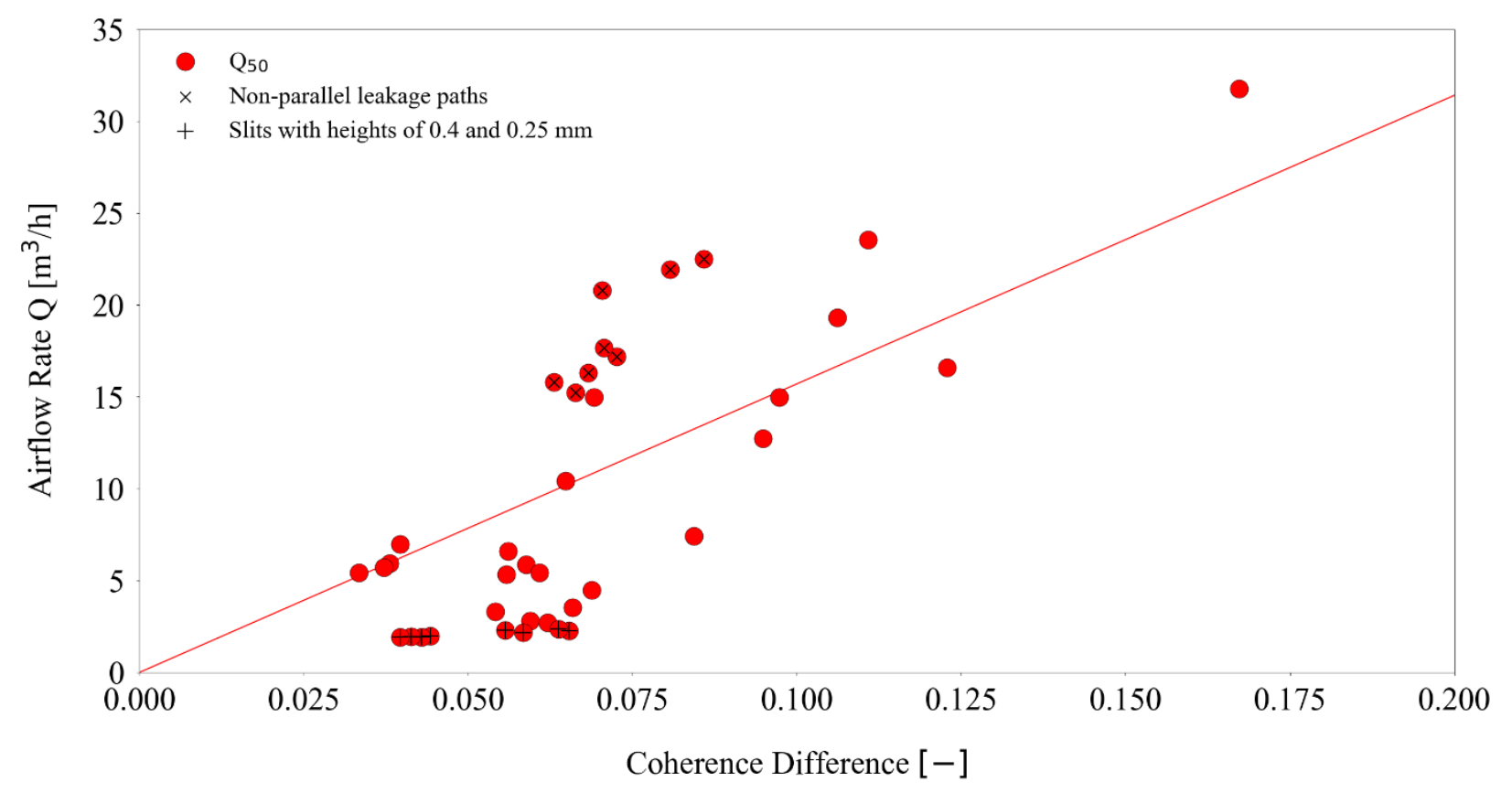

Figure 7: Correlation between mean coherence difference and different airflow rates at $50 \mathrm{~Pa}$ pressure difference for all investigated leakage configurations 


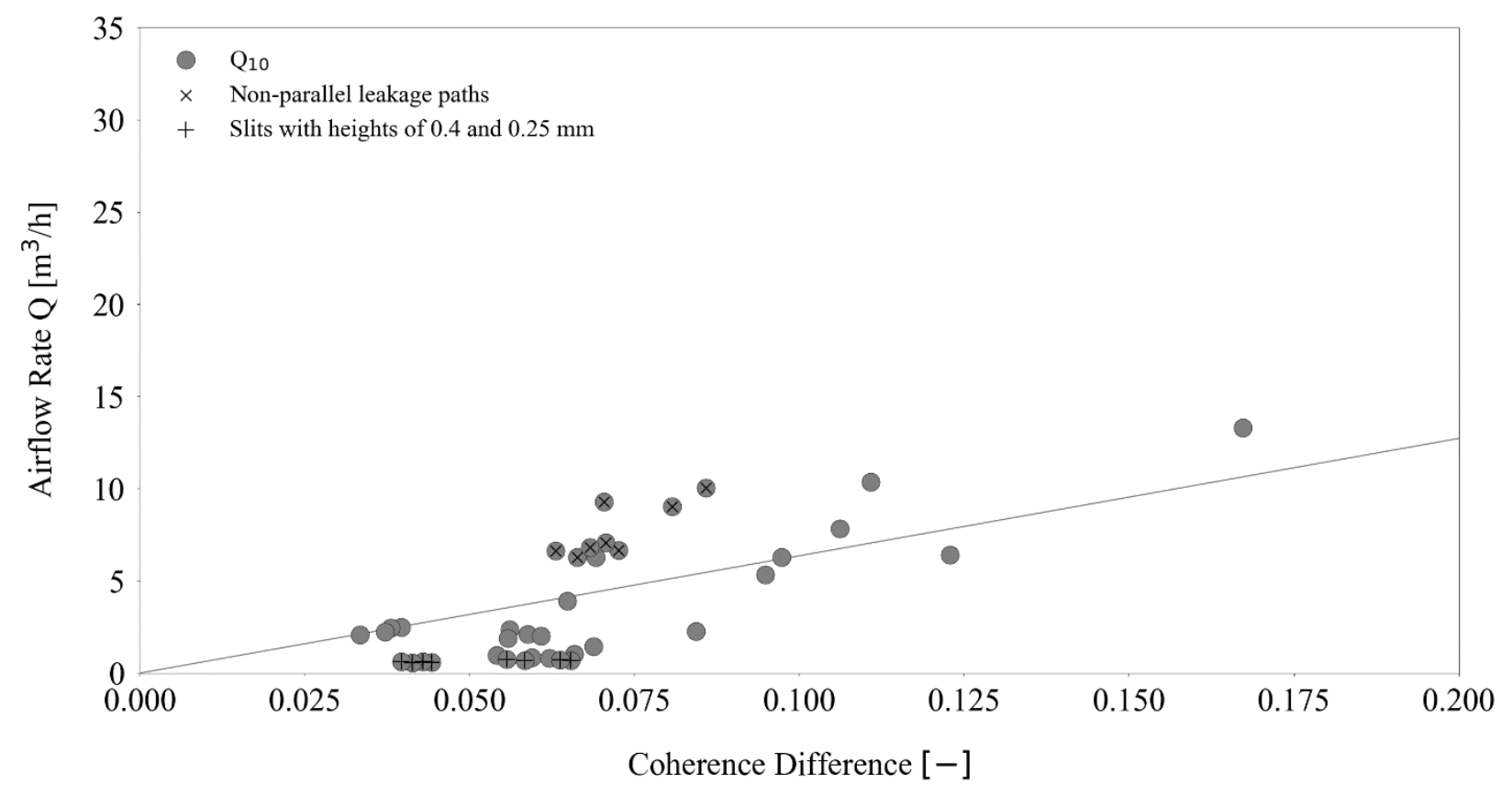

Figure 8: Correlation between mean coherence difference and different airflow rates at 10 Pa pressure difference for all investigated leakage configurations

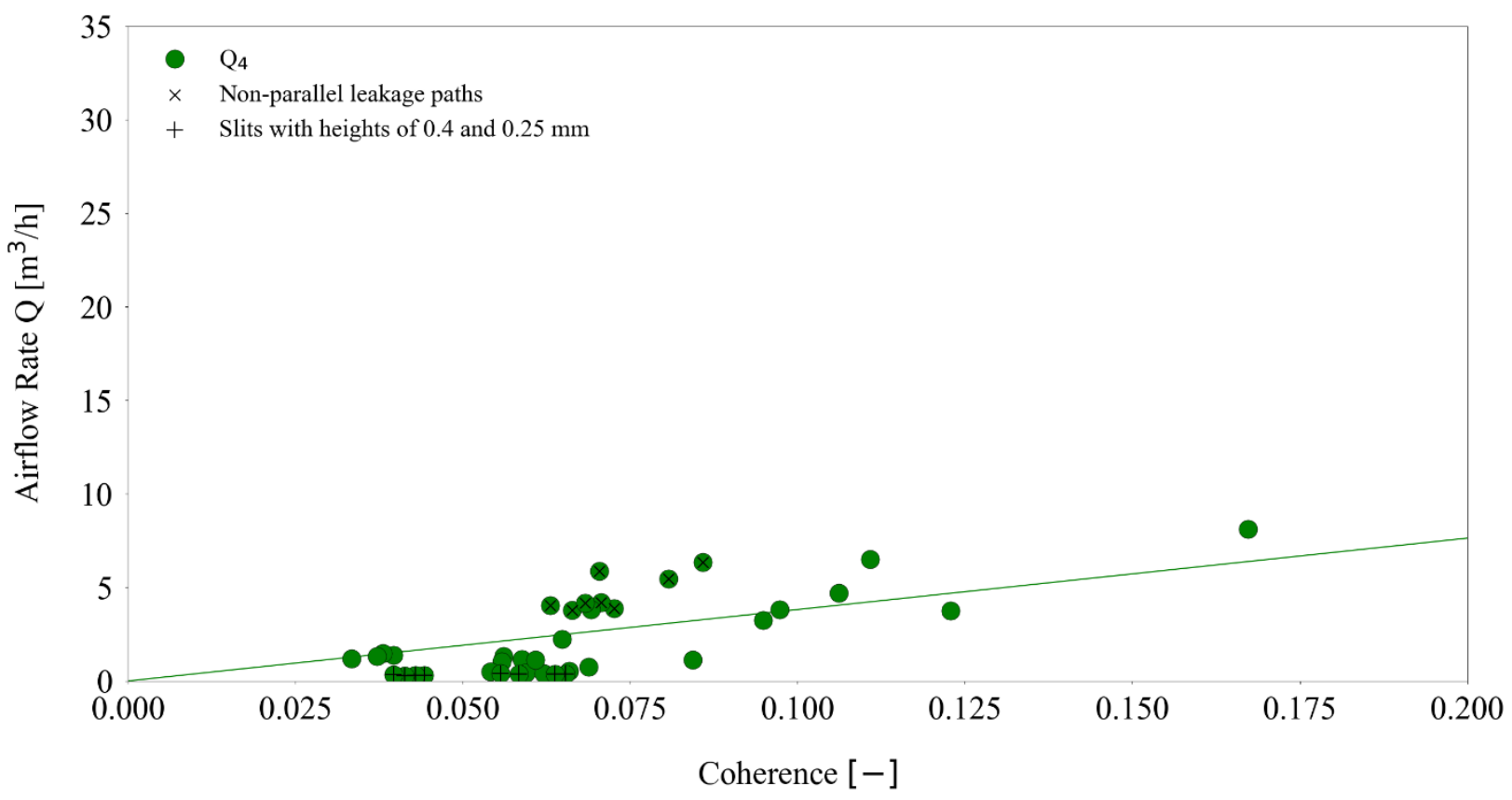

Figure 9: Correlation between mean coherence difference and different airflow rates at 4 Pa pressure difference for all investigated leakage configurations

Figures 7-9 show an observable trend between coherence and airflow for a given pressure difference. This 
indicates that the coherence can be used to predict air leakage. To investigate this trend, the coherence function values $\left(C_{x y}\right)$ were related to the airflow using the following Equation for each of the three pressures in Figures 7-9:

$$
Q=K C_{x y} \Delta P^{n_{C}}
$$

Where $\Delta \mathrm{P}$ is equal to each of the three references pressures $(4,10$, and $50 \mathrm{~Pa})$ and coefficient $K\left(\mathrm{~m}^{3} /\left(\mathrm{h} \cdot \mathrm{Pa}^{\mathrm{n}}\right)\right)$ and pressure exponent $n_{C}(-)$ were determined using an optimizer at each pressure. The optimizer uses nonlinear least squares to fit Equation 4 to the data. For each pressure case, the pressure exponent $n_{C}$ was close to 1 . Figure 10 shows the fitted $n_{C}$ and $K$ values for the three investigated pressure differences. The fitted coefficients $K$ indicate a non-linear relationship between $K$ and the pressure difference.

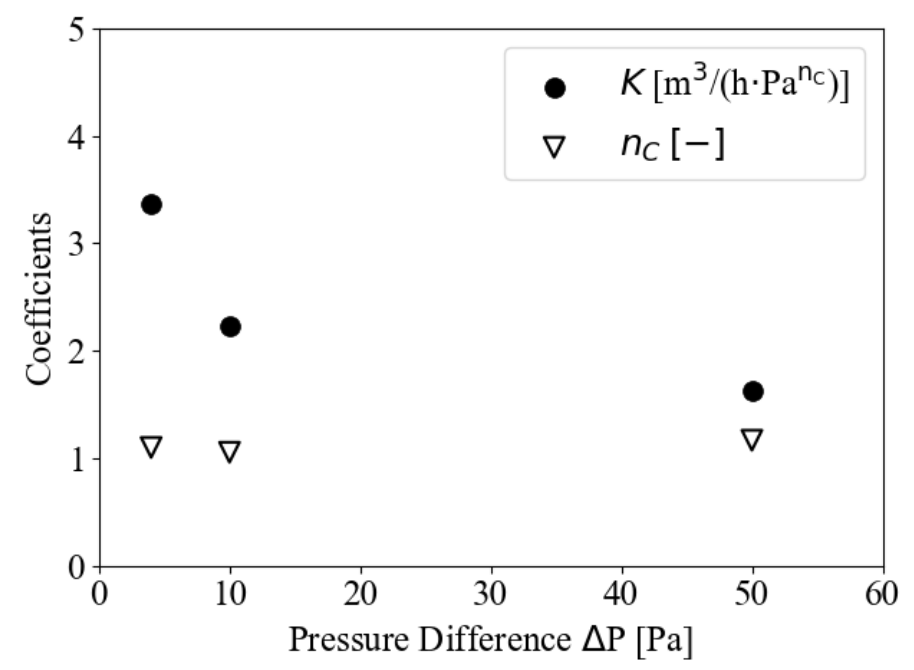

Figure 10: Fit of coefficient $K$ and exponent $n_{C}$ for the investigated pressure differences in the laboratory tests

The thin lines in Figures 7-9 show the resulting flow-coherence relationship. From these figures, we can also observe that different leak configurations can have similar coherence but quite different airflow. Further spectral analysis may be combined with the coherence to improve the acoustic estimates of leakage and airflow in future work. For example, a possible weighting of certain dominant frequency bands, instead of taking a mean value over the whole frequency range, may have the potential to increase the prediction accuracy. 
In order to assess the accuracy of the prediction of airflow rates with the relationship introduced in Equation 4, the absolute root mean square error (RMSE) and a normalized root mean square error (NRMSE) between the measured (meas) airflow rates and the predicted (pred) function were calculated (see Equation 5 and 6). The NRMSE is normalized by the predicted flow rate of the airflow at the specific pressure differences to be able to compare this error for different scales.

$$
\begin{gathered}
R M S E=\sqrt{\frac{\sum_{i=1}^{N}\left(Q_{i, \text { meas }}-Q_{i, \text { pred }}\right)^{2}}{N}} \\
N R M S E=\sqrt{\frac{\sum_{i=1}^{N}\left(\frac{Q_{i, \text { meas }}-Q_{i, \text { pred }}}{Q_{i, \text { pred }}}\right)^{2}}{N}}
\end{gathered}
$$

These errors for flow rate predictions at 4, 10, and 50 Pa pressure difference are shown in Table 1.

Table 1: RMS errors for flow predictions

\begin{tabular}{c|ccc} 
& $\mathbf{Q}_{\mathbf{5 0}}$ & $\mathbf{Q}_{\mathbf{1 0}}$ & $\mathbf{Q}_{\mathbf{4}}$ \\
\hline $\mathbf{R M S E}\left(\mathbf{m}^{\mathbf{3}} \mathbf{h}\right)$ & 5.42 & 2.48 & 2.44 \\
NRMSE (-) & 0.53 & 0.59 & 0.63 \\
\hline
\end{tabular}

The absolute RMSE decreases with predicting airflow rates at lower pressure differences, whereas the NRMSE decreases with airflow rates at increasing pressure differences. The NRMSE indicate errors of greater than $+/-50 \%$ for the prediction of airflow rates with the acoustic method.

Additionally, two prominent leak configurations were highlighted in the Figures 7-9 to indicate some significant outliers from this general trend. Firstly, all non-parallel leakage paths (cf. Figure $2 \mathrm{f}$ ) and g)) are highlighted with an additional ' $x$ ' on the dots in Figures 7-9. These are all grouped in the top left part of the 
figures. For all configurations with non-parallel leakage paths (with and without a connecting channel), only slits with heights of 5 and $1 \mathrm{~mm}$ were manufactured. Here, the acoustic measurement procedure generally underestimates the actual leak size. One explanation might be that soundwaves are attenuated due to reflection inside the structure. Therefore, this acoustic method might be less suitable for quantifying airflows in constructions with large non-parallel airflow paths.

Secondly, the leak configurations containing only the smallest slits with heights of only 0.4 and $0.25 \mathrm{~mm}$ (cf. Figure $2 \mathrm{~h}$ )) are highlighted with an additional ' + ' on the dots. These are all grouped in the bottom part of Figures 7-9. Even though the measured airflow through these leaks does not differ significantly (e.g., for different distances in the double wall configurations), there is a variation in the coherence difference for this group of artificial leaks. Therefore, the influence of the sound transmission through the wall structure itself seems to dominate these measurements compared to the sound transmission through these tiny leaks. This makes it hard to detect these small leaks correctly using this method.

However, the acoustic parameter may not serve the purpose of precisely predict the airflow, but it may have the potential to give an order of magnitude.

\section{EXPERIMENTAl SETUP Window FAÇADE}

Having established the experimental procedure using artificial leaks in a controlled laboratory setting, this next section discusses measurements made on a window in a real office building using the same experimental technique.

\subsection{Methodology}

\subsubsection{Test Site and Investigated Leaks}

The test site is a small office (dimensions of the room: $3.6 \mathrm{~m} \mathrm{x} 5.4 \mathrm{~m} \times 3.0 \mathrm{~m}$ ) at ground level with a window façade (one wall) as part of the building envelope. Within this window façade, six leaks of different sizes were artificially constructed and tested. A varying number of cable ties were wedged at the same place 
of one window frame to simulate a damaged window gasket and to create reproducible leaks. Two types of cable ties were used to achieve this: a lager tie (top row of Figure 11) with a width and height of $8.0 \times 1.5 \mathrm{~mm}$ and a smaller one (bottom row of Figure 11) with a $3.0 \times 1.0 \mathrm{~mm}$ width and height, respectively. The ties were screwed to a small piece of wood to ensure they remain rigid during the measurements. Figure 12 shows how the cable ties were inseted in the window frame.
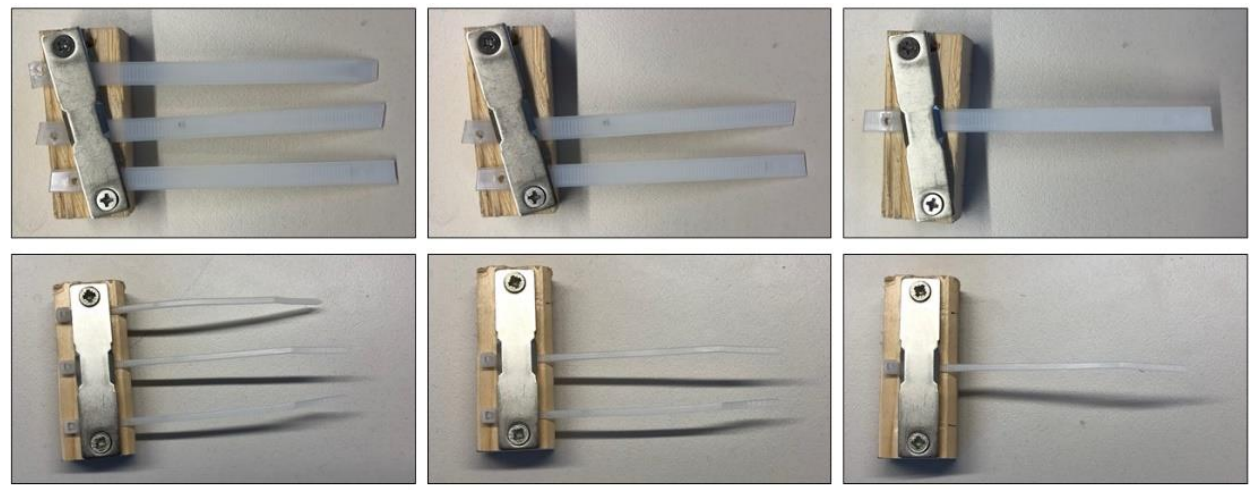

Figure 11: The two types of cable tie used to create reproducible artificial leaks in the window frame. Top row: large cable ties with an $8 \mathrm{~mm}$ width, bottom row: small cable ties with a $3 \mathrm{~mm}$ width

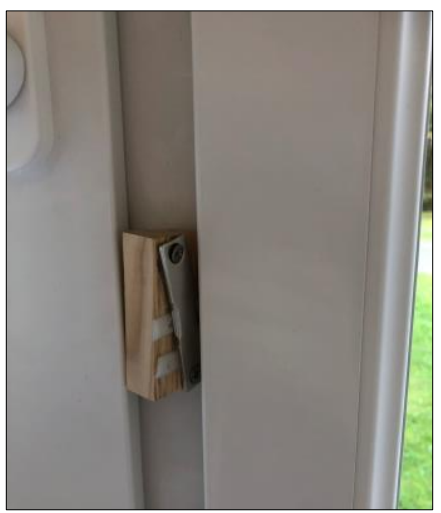

Figure 12: Insertion of cable ties in the window frame 


\subsubsection{Airflow and Pressure Difference Measurements}

In order to measure the flows through the deliberate window leaks only, we constructed a solid wooden frame (see Figure 13, left side) that fit precisely over the window containing the leaks. This frame was covered with an airtight foil and sealed to the ambient room to create a closed control volume of the window. After that, a duct with a controllable fan and a venturi airflow meter was connected to the frame (see Figure 13, right side). Similar to the method described in chapter 2.1.3., the pressure difference across the calibrated airflow meter was measured and converted to the airflow rate afterward.

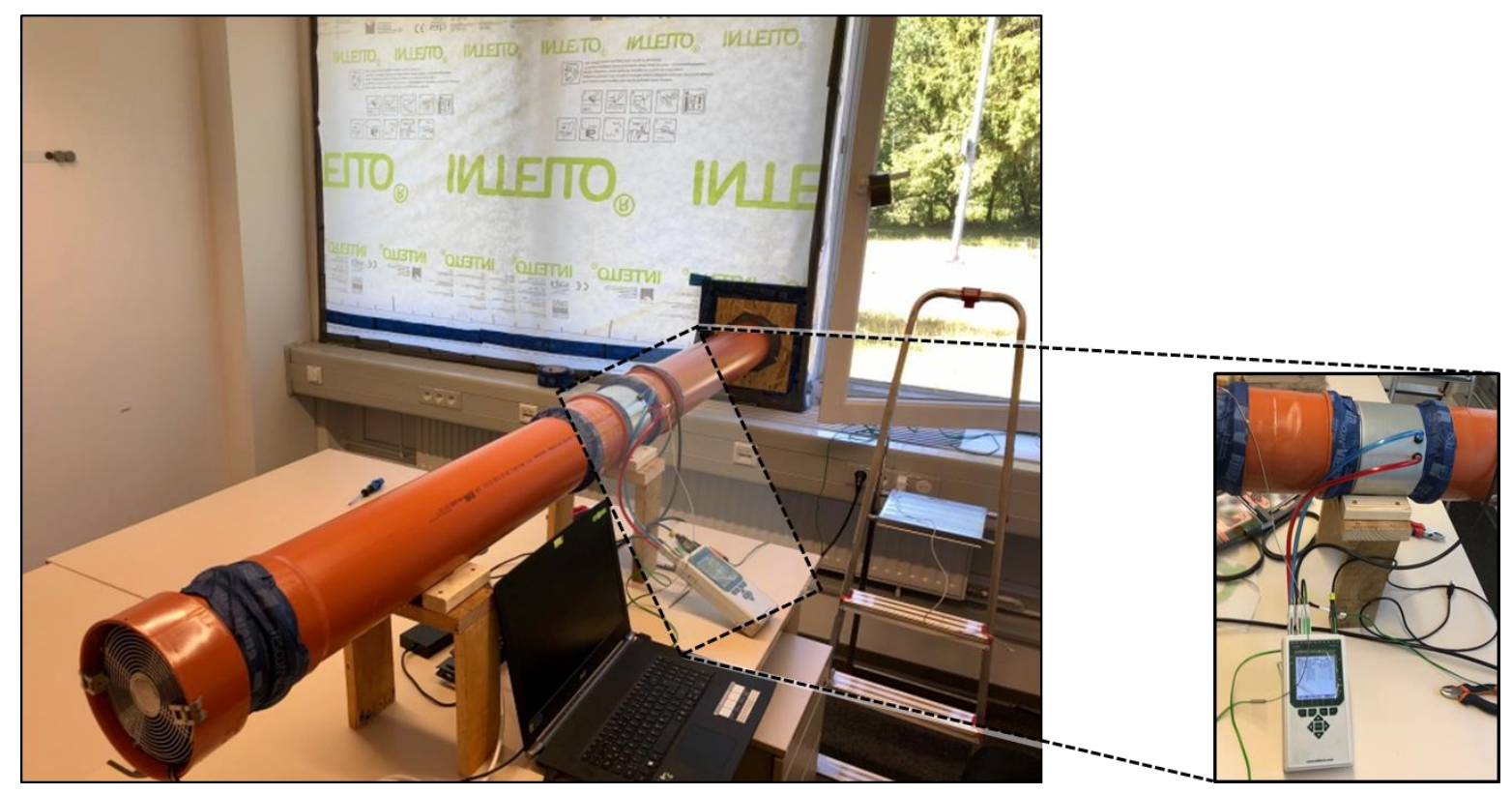

Figure 13: Experimental setup for airflow and pressure difference measurements in an office building (left) with venturi airflow meter (right)

Pressure taps were connected to the frame to measure the pressure differences across the window simultaneously to the airflow measurements. Temperature measurements were taken inside and outside the room, and corrections were applied to readings from the flow measurement system following the ASTM standard [4]. 


\subsubsection{Acoustic Measurements}

For the acoustic measurements, a pair of high and mid/low-frequency omni-directional speakers were placed in the middle of the office room (see Figure 14 a)). The high-frequency speaker has an even frequency range of 1-120 kHz, and the low-frequency dodecahedron speaker has an even frequency range of 0.05-16 kHz. However, during the tests, we recognized that this speaker was capable of emitting signals up to $40 \mathrm{kHz}$, even though it was not guaranteed by its manufacturer. The emitted signal was a broadband white noise, recorded with a sampling frequency of $192 \mathrm{kHz}$. Thus, according to Shannon [44], frequencies up to $96 \mathrm{kHz}$ can be analyzed. One microphone recorded the emitted signal inside the room next to the speakers, and a second microphone was placed outside the window (see Figure $14 \mathrm{~b}$ )). The microphones were the same as used in the laboratory measurements.

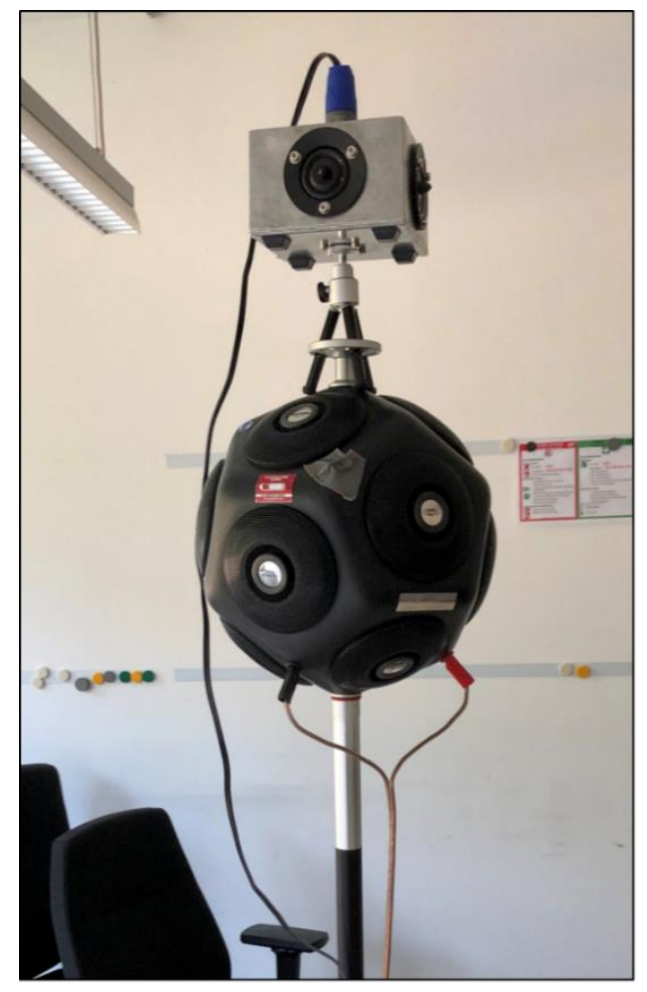

a)

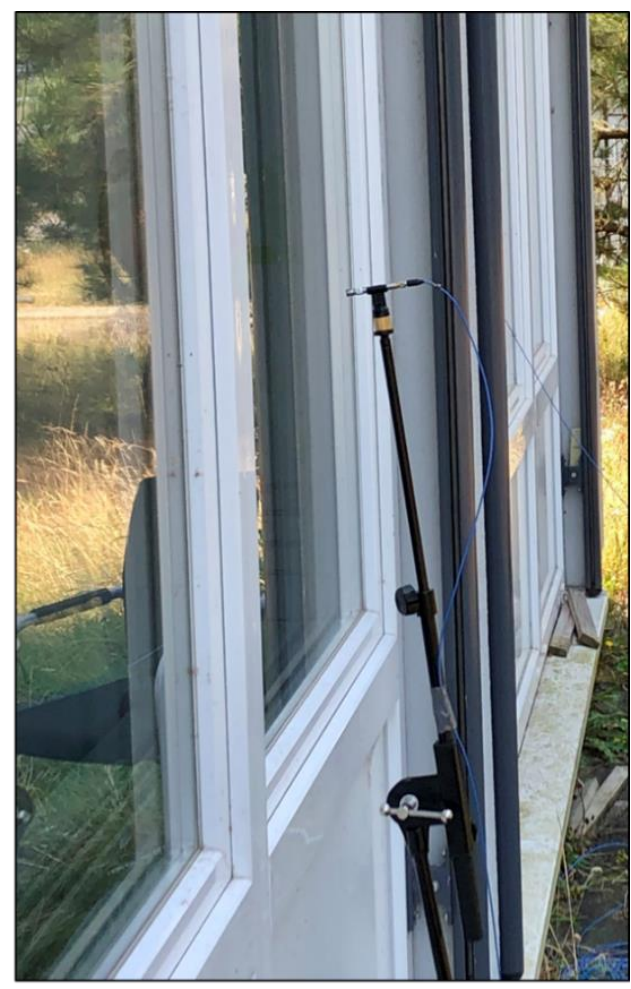

b)

Figure 14: High frequency (top) and mid/low frequency (bottom) omnidirectional dodecahedron speaker (a) and microphone outside the building (b) 


\subsection{RESUltS AND DiscuSSION OF Window FAÇADE MEASUREMENTS}

\subsubsection{Airflow and Pressure Difference Measurements}

For all six different constructed leaks, airflow and pressure difference measurements were conducted. The results of all measurements in the office room with multiple pressure levels are shown in Figure 15. The three blue lines in the upper part of the plot indicate the fit according to the power-law (cf. Equation 2) for the larger cable tie with a diameter of $8 \mathrm{~mm}$. In the lower part of the plot, the three green lines show the measurement fit of the smaller cable tie with a $3 \mathrm{~mm}$ diameter. The term " $3 \times 8 \mathrm{~mm}$ " means that, for instance, 3 cable ties with a diameter of $8 \mathrm{~mm}$ are wedged in the window frame at the same time (see the top left configuration in Figure 11).

Here, a clear distinction between all six measurements and leak configurations is possible. However, there is significantly higher uncertainty in the flow measurements for the three smallest leak configurations with a smaller airflow (in green). Again, the black dotted vertical lines indicate the pressures at 50, 10, and $4 \mathrm{~Pa}$ pressure difference, which are chosen for the subsequent analysis. Similar to the laboratory measurements, the airflow rates at these pressure values are extracted from the measurements shown in Figure 14 by interpolation along the fitted curve. 


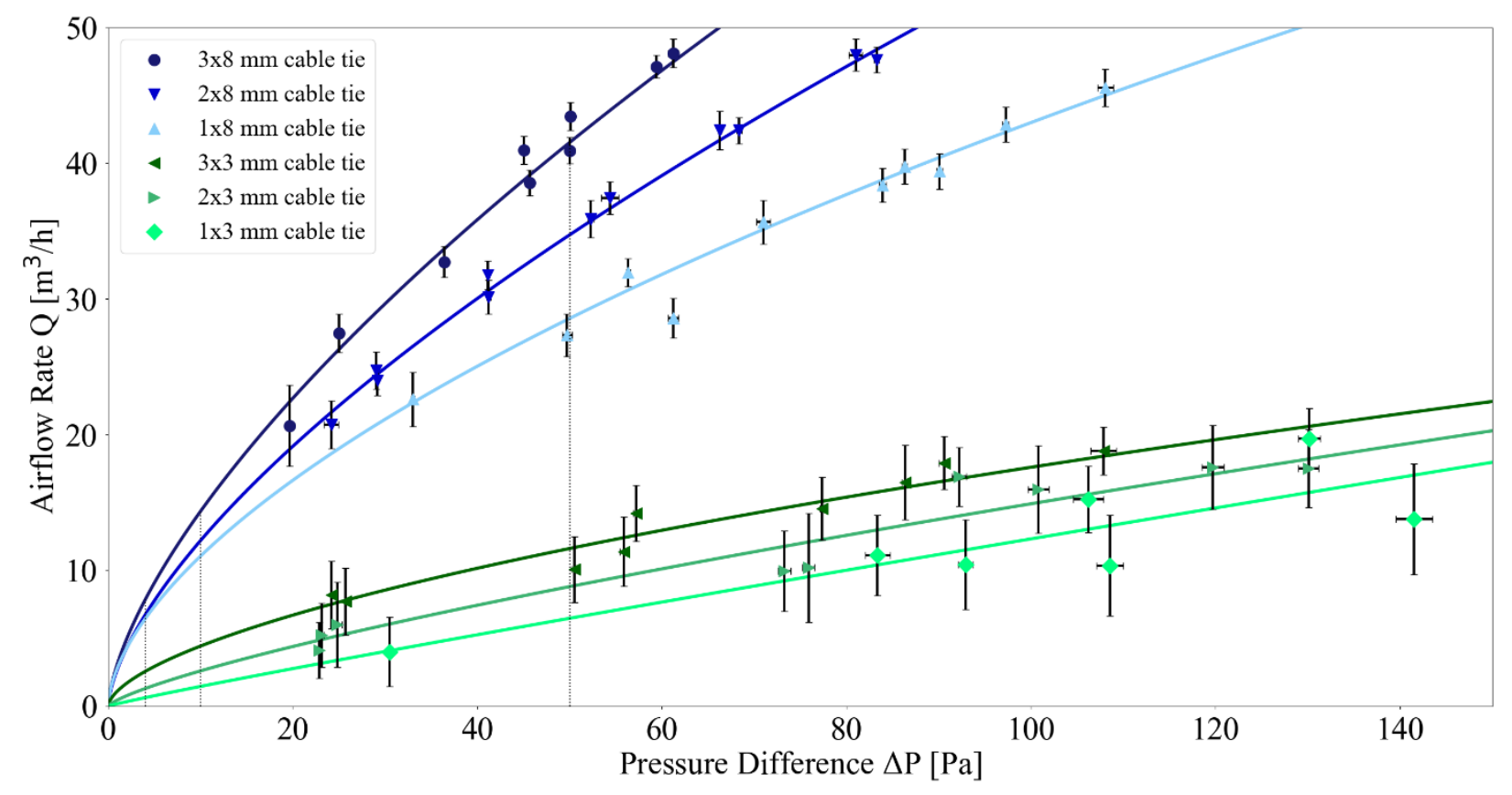

Figure 15: Airflow-pressure measurement of constructed leaks with cable ties wedged in the window frame on a linear scale, including measurement uncertainties

\subsubsection{Acoustic Measurements}

The coherence functions of both recorded acoustic signals from the microphones inside and outside the office room are calculated. Similar to the laboratory testing, measurements were made with the window closed and no artificial leaks in order to measure the sound transmission through the window and façade to be subtracted from the leak coherence measurements. Figure 16 shows the coherence function for the window without any artificial leak as a function of the frequency. The thin blue line is the calculated function, and the thicker black line is a calculated moving average value for better visualization with less noise. In this measurement, notably lower frequencies $(<10 \mathrm{kHz})$ appear to be coherent between both signals. At higher ultrasonic frequencies $(>20 \mathrm{kHz})$, the coherence of inside and outside measurement is close to 0 . 


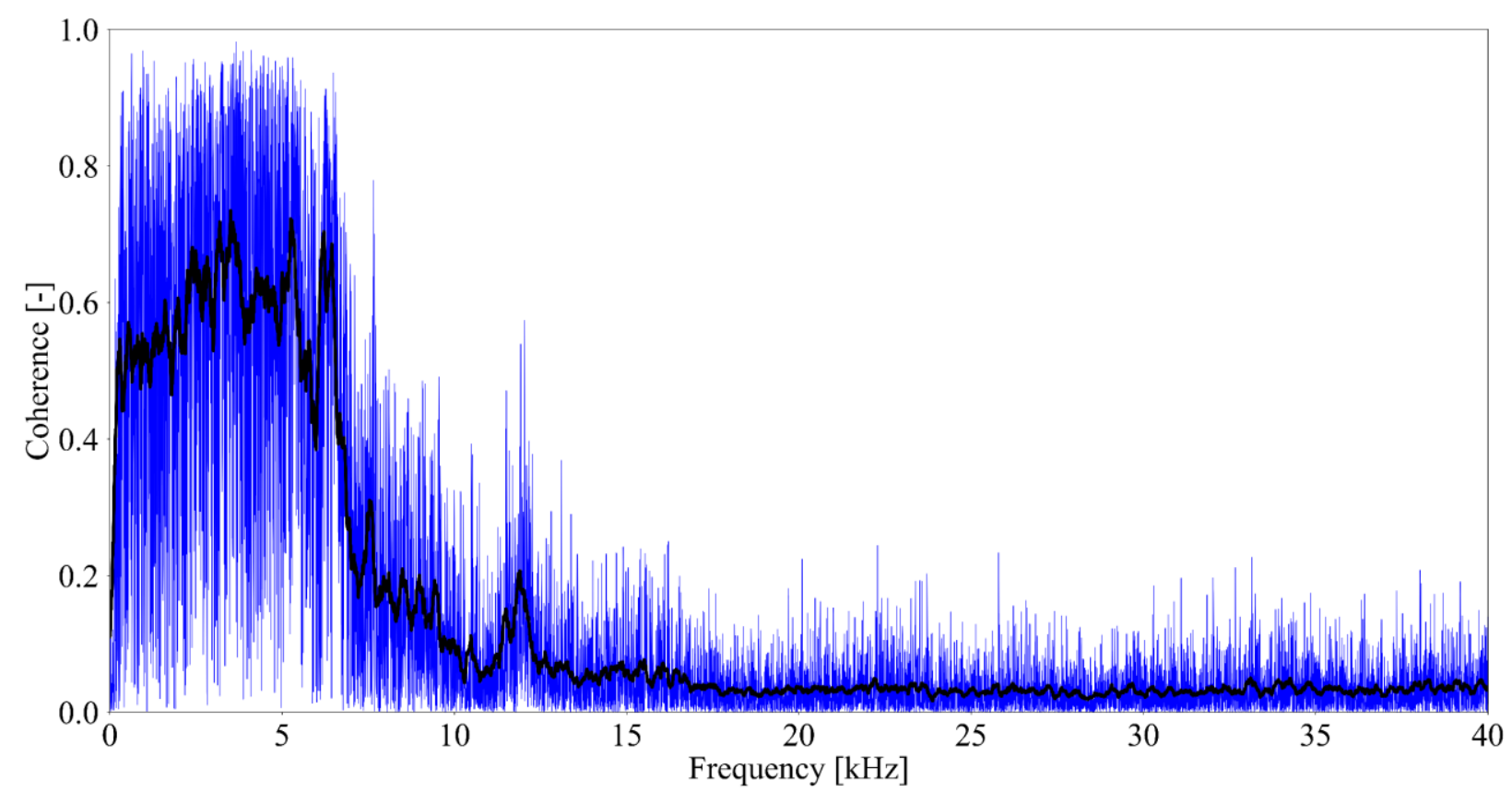

Figure 16: Coherence of building measurement with the tight window, with the black line indicating the moving average

These results show how signal energy through the window is transmitted, even though the window is airtight, and this measured coherence will be subtracted from measurements with added leaks.

Figure 17 shows the measured coherence for the deliberately added leaks without the no leak results in Figure 16 subtracted. The thin lines (in red) represent the calculated coherence values, and the bold black line the moving averages of the same function. These measurements exhibit a clear contrast compared to the measurements without added leaks (cf. Figure 16). In addition to the already transmitted frequencies $(<10 \mathrm{kHz})$ from the window itself, responses at higher frequencies can be observed that are caused by openings in the window.

The largest opening, where three large cable ties have been wedged in the window frame, shows a relatively strong coherence (sometimes more than 0.6) for frequencies up to $35 \mathrm{kHz}$. As well as the change in frequency response, the magnitude of the coherence function decreases with decreasing opening size. 

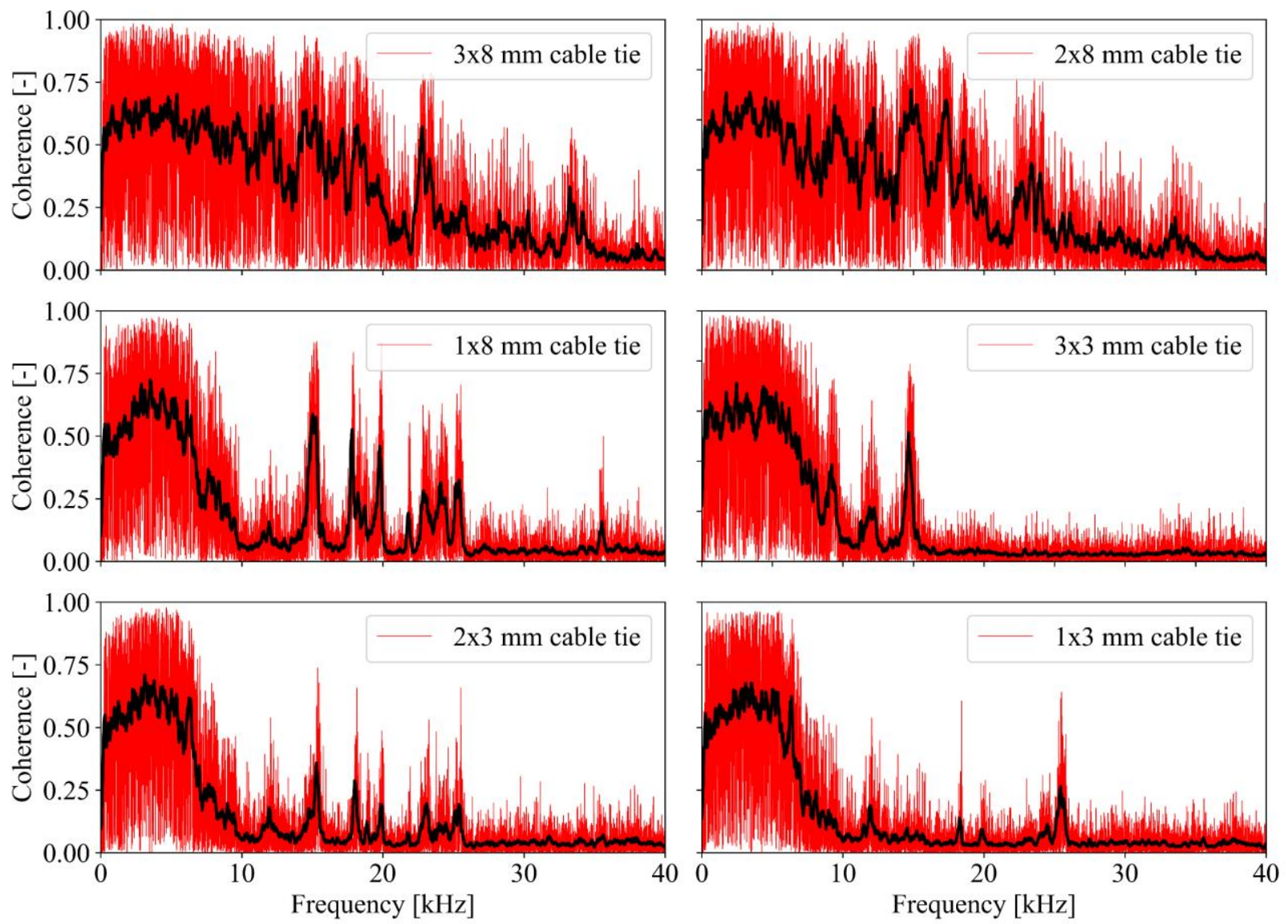

Figure 17: Coherence of building measurements with constructed leaks, with the black lines indicating the moving average

For smaller openings, specific frequencies appear to dominate. For the four smaller leaks, the response below $10 \mathrm{kHz}$ is very close to that for the window with no leaks.

Next, the coherent frequencies from the test with no leaks, as shown in Figure 16, were subtracted from the measurements which contain openings, to exhibit sound transmission at frequencies only affected by the openings. These results are shown in Figure 18. The frequencies can be interpreted at frequencies of dominant sound transmission depending on the size of the specific leaks. These results show some of the same trends as the laboratory tests: an increasing magnitude of coherence with increased leak size for the $8 \mathrm{~mm}$ tests. However, the results using the $3 \mathrm{~mm}$ cable ties are less clear. Possibly a mean coherence value would show the trend more clearly. With most of the response below $10 \mathrm{kHz}$ removed, characteristic 
frequency spikes are observed above that frequency. A spike at about $15 \mathrm{kHz}$ is observed for the $1 \mathrm{x} 8,3 \times 3$, and $2 \times 3 \mathrm{~mm}$ cases. The $1 \times 8$ and $2 \times 3 \mathrm{~mm}$ cases also show similar responses at higher frequencies between 15 and $25 \mathrm{kHz}$. These are absent from the $3 \times 3 \mathrm{~mm}$ case. Finally, the $1 \times 3 \mathrm{~mm}$ case does not show the same sub-25 kHz responses of the other cases and has a strong response just above $25 \mathrm{kHz}$. While these results do not show any particular characteristic trends, they indicate that spectral analyses may help characterize other aspects of leaks beyond their scalar size, such as determining the pressure exponent $n_{C}$.
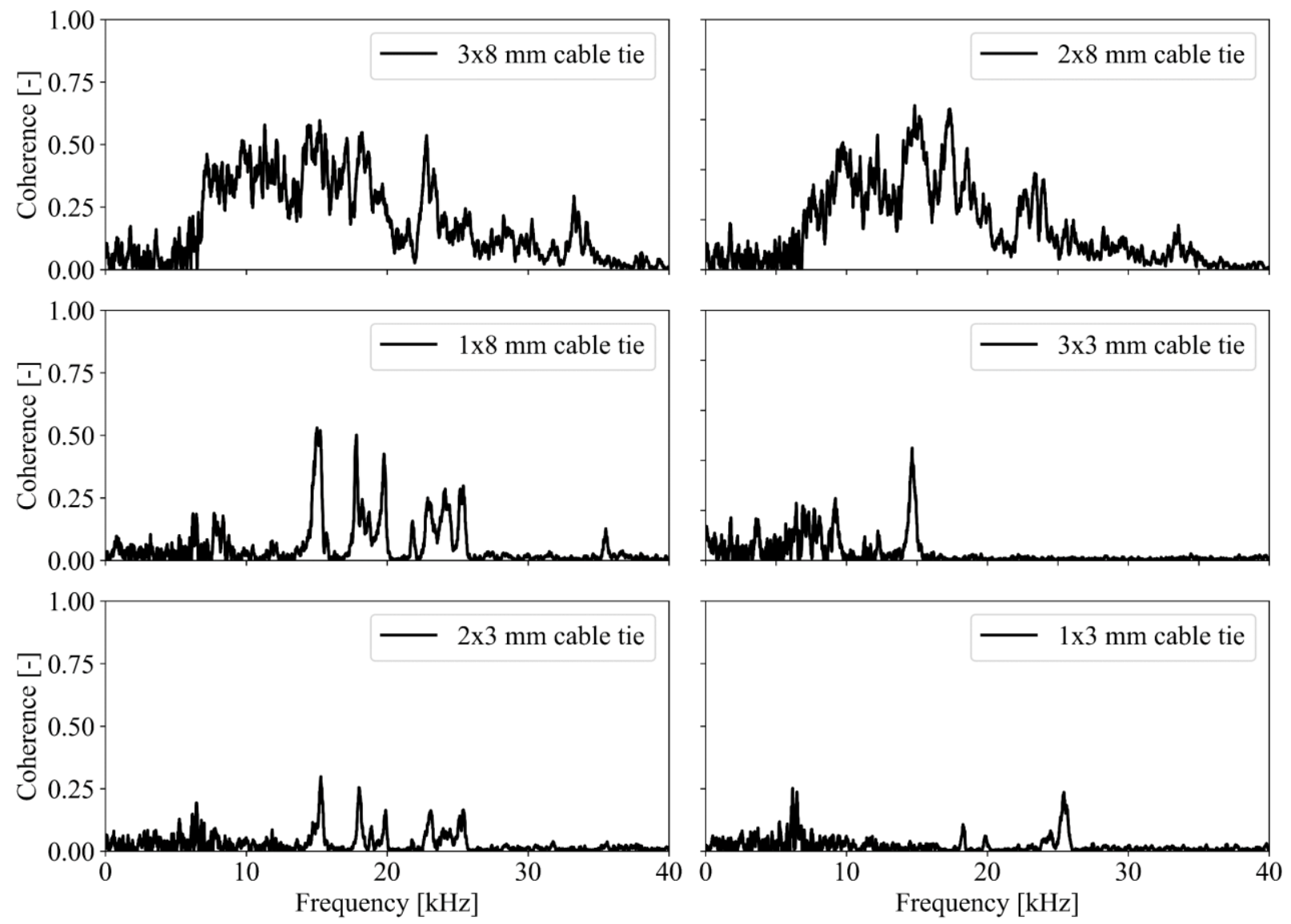

Figure 18: Moving average of differences between the coherence of constructed leaks and tight widow

In the last step, the mean difference of measured leak coherence and the reference measurement over the chosen frequency range is defined as a measure of the leak size and plotted against the airflow rates at 50 (red), 10 (black), and $4 \mathrm{~Pa}$ (green) pressure difference. This comparison between acoustic and airflow metrics is shown in Figure 19. The airflow values are taken from the measurements shown in Figure 15. 
The thin lines in Figure 19 are the relationships introduced in Equation 4, with optimized $\mathrm{K}$ and $\mathrm{n}_{\mathrm{C}}$ values for the airflow rates at the respective pressure differences $\left(\mathrm{Q}_{50}, \mathrm{Q}_{10}\right.$, and $\left.\mathrm{Q}_{4}\right)$ and the mean differences of the calculated coherence within the considered frequency range. The three dots above each line (for $\mathrm{Q}_{50}$, $\mathrm{Q}_{10}$, and $\mathrm{Q}_{4}$ ) correspond to the leaks with the larger cable tie (8 $\mathrm{mm}$ width), and the three dots below each line correspond to the leaks with the smaller ones ( $3 \mathrm{~mm}$ width). Similar to the laboratory experiments, these correlations between airflow and acoustic parameters show a general trend that with increasing leak size, the difference of the coherence measurements increases as well. Similar to changes in airflow path/leak configuration in the earlier laboratory measurements, the substantial increase in airflow rate between these two types of cable ties, which is visible in Figure 15 between the group of green and blue lines, is not directly represented by the acoustic measurements. The increase in the mean coherence difference between these groups of leaks is much smaller. This would lead to an overestimation of the leak size for the small leak configurations and underestimating the leak size for larger leaks if one would only consider the acoustic measurements. Nevertheless, a prediction of an order of magnitude might be possible. As with the laboratory testing, the different window leaks had different spectral properties (as shown in Figure 18), and this shows some potential for future spectral analyses to improve the relationship between acoustic coherence measurements and predicted air leakage.

The fitted $K$ and $n_{C}$ values for the three investigated pressure differences are finally illustrated in Figure 20 for the building tests. As for the laboratory tests, these fitted coefficients for $n_{C}$ are close to 1 and the fitted coefficients for $K$ indicate a non-linear relationship between this coefficient and the pressure difference. The coefficients $K$ at 50 and $10 \mathrm{~Pa}$ are in the same magnitude as for the laboratory tests. However, the $K$ value at $4 \mathrm{~Pa}$ is a bit higher. The uncertainties in the flow measurements are, particularly at low pressures and flows, higher for the measurements in the building compared to the laboratory measurement, which could explain this deviation. 


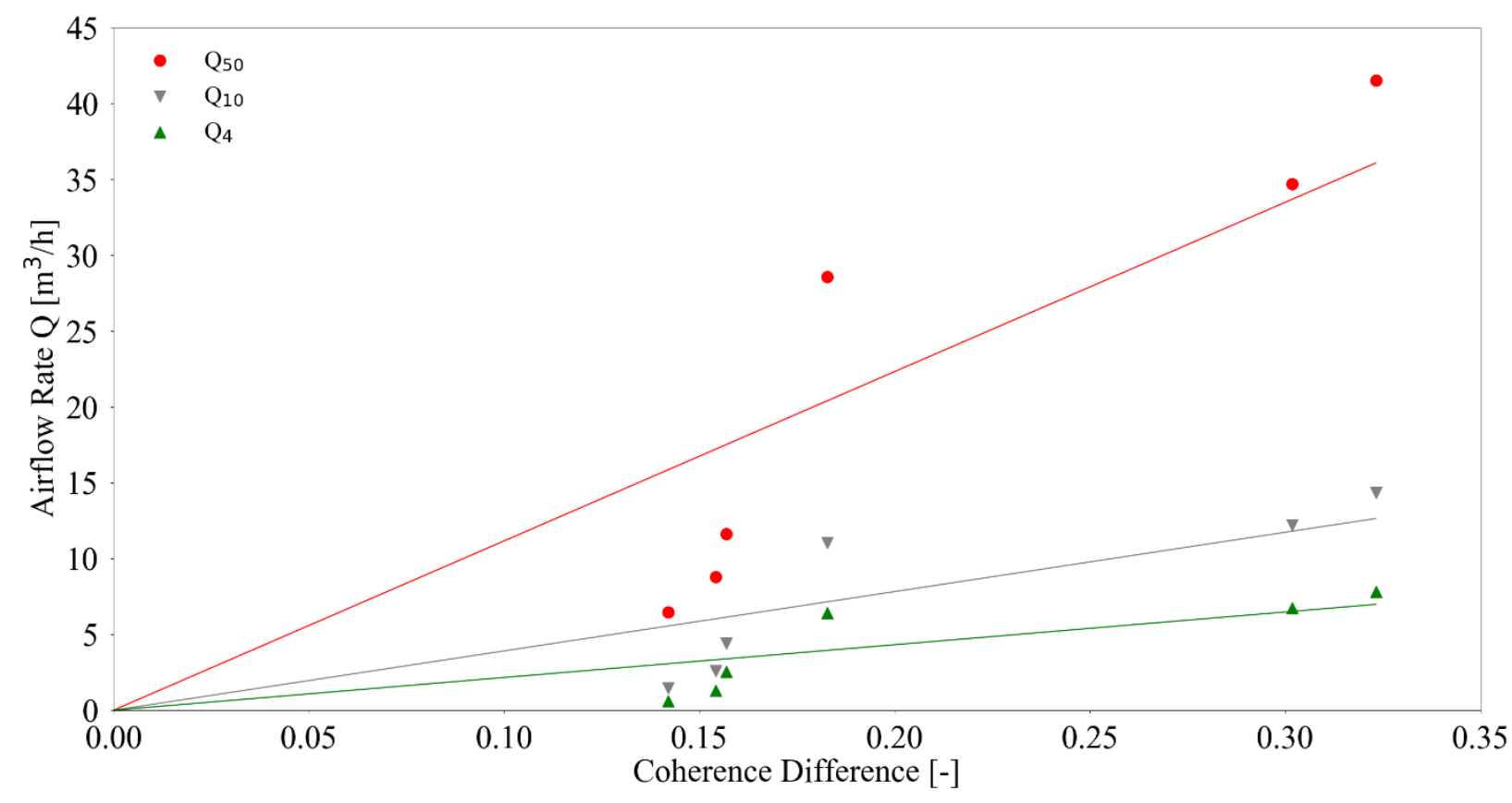

Figure 19: Comparison of the measurements of airflow rate with coherence differences of constructed leaks and the tight window

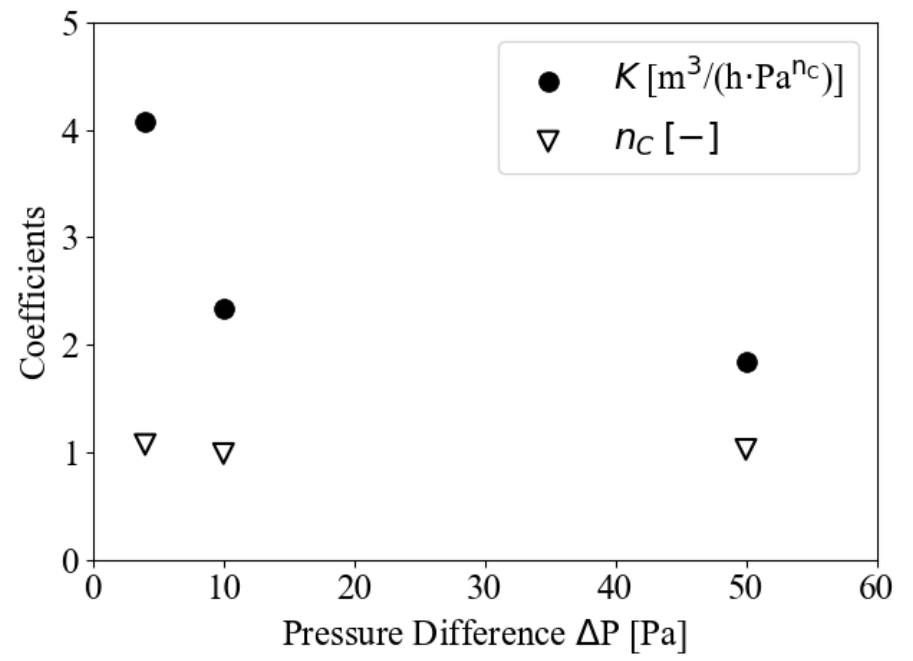

Figure 20: Fit of coefficient $K$ and exponent $n_{C}$ for the investigated pressure differences in the building tests

\section{CONCLUSions AND Future Work}

In this work, an acoustic method was proposed to quantify the air leakage in a laboratory test apparatus and 
validate this method in a real building application. Fan pressurization and acoustic measurements were performed in both experimental setups. Within both arrangements, the acoustic approach combined with a measurement of pressure difference gave an estimate of the magnitude of airflow, which passes through a single leak. From the test results, we can conclude that the acoustic coherence measurements change with different leaks. There is a linear trend of increasing coherence with increasing leakage that indicates the potential for this acoustic technique as a building diagnostic; however, the uncertainties were significant (greater than $+/-50 \%$ ).

Observations of the spectral acoustic results indicate that additional spectral analysis may be able to better identify different leak types and reduce these uncertainties. This remains a topic for future work. Other future work could investigate more complex leak configurations and the localization of leaks in real buildings. For an application in buildings, a study is currently under way that is using microphone arrays to detect leak locations. It is possible that in the future these methods could be combined such that leak sizes could be estimated for specific leak locations.

\section{NomenClature}

\section{Abbreviations}

ELA Equivalent Leakage Area $\mathrm{m}^{2}$

MDF Medium-Density Fiberboard

RMS Root Mean Square

\section{Latin Symbols}

$\begin{array}{lll}\text { A } & \text { Cross-sectional area of Venturi airflow meter } & \mathrm{m}^{2} \\ \mathrm{C} & \text { Flow coefficient } & \mathrm{m} /\left(\mathrm{h} \cdot \mathrm{Pa}^{\mathrm{n}}\right) \\ \mathrm{C}_{\mathrm{xy}} & \text { Coherence function } & - \\ \mathrm{G}_{\mathrm{xy}} & \text { Cross-spectral density between time signal } \mathrm{x} \text { and } \mathrm{y} & \mathrm{W} / \mathrm{Hz}\end{array}$




$\begin{array}{lll}\mathrm{G}_{\mathrm{xx}} & \text { Auto-spectral density between time signal } \mathrm{x} \text { and } \mathrm{x} & \mathrm{W} / \mathrm{Hz} \\ \mathrm{G}_{\mathrm{yy}} & \text { Auto-spectral density between time signal y and } \mathrm{y} & \mathrm{W} / \mathrm{Hz} \\ \mathrm{K} & \text { Coefficient } & \mathrm{m}^{3} /\left(\mathrm{h} \cdot \mathrm{Pa}^{\mathrm{n}}\right) \\ \mathrm{N} & \text { Number of data points } & - \\ \mathrm{n} & \text { Pressure exponent } & - \\ \mathrm{n}_{\mathrm{C}} & \text { Pressure exponent determined by acoustic measurements } & - \\ \mathrm{P} & \text { Pressure } & \mathrm{Pa} \\ \mathrm{Q} & \text { Airflow } & \mathrm{m} / \mathrm{h} \\ \mathrm{x}, \mathrm{y} & \text { Discrete time signals } & -\end{array}$

\section{Greek Symbols}
$\Delta$
Difference
$\rho$
Density of air
$\mathrm{kg} / \mathrm{m}^{3}$

\section{Subscripts}

$\begin{array}{ll}4 & \text { Evaluated at } 4 \text { Pa pressure difference } \\ 10 & \text { Evaluated at } 10 \mathrm{~Pa} \text { pressure difference } \\ 50 & \text { Evaluated at } 50 \mathrm{~Pa} \text { pressure difference } \\ \mathrm{i} & \text { Single measurement point } \\ \text { meas } & \text { Measured Value } \\ \text { pred } & \text { Predicted Value }\end{array}$

\section{ACKNOWLEDGMENTS}

The presented work was embedded in a research project of the German Aerospace Center (DLR), which is funded by the German Ministry for Economic Affairs and Energy [grant number 03ET1405A] in cooperation with the Lawrence Berkeley National Laboratory (LBNL), CA, USA. Additional funding was provided by the U.S. Dept. of Energy under Contract No. DE-AC02-05CH11231. 


\section{REFERENCES}

[1] International Energy Agency, Energy-efficient Buildings: Heating and Cooling Equipment, OECD Publishing, Paris, 2011.

[2] W.R. Chan, M.H. Sherman, Analysis of Air Leakage Measurements from Residential Diagnostic Database: Report, Berkeley, CA, 2012.

[3] K. Pietrzyk, Thermal Performance of a Building Envelope - A Probabilistic Approach, Journal of Building Physics 34 (2010) 77-96. https://doi.org/10.1177/1744259109339652.

[4] ASTM, E779-19 Test Method for Determining Air Leakage Rate by Fan Pressurization, ASTM International, West Conshohocken, PA 91.140.30, 2019.

[5] DIN EN ISO, 9972:2018-12, Thermal performance of buildings - Determination of air permeability of buildings - Fan pressurization method, 12th ed., Beuth Verlag GmbH, Berlin 9972:2018, 2018.

[6] CAN/CGSB, 149.10-2019 Determination of the Airtightness of Building Envelopes by the Fan Depressurization Method, Canadian General Standards Board, Gatineau 91.120.10, 2019.

[7] I.S. Walker, D.J. Wilson, Field Validation of Algebraic Equations for Stack and Wind Driven Air Infiltration Calculations, HVAC\&R Research 4 (1998) 119-139. https://doi.org/10.1080/10789669.1998.10391395.

[8] ASTM, E1186-17 Standard Practices for Air Leakage Site Detection in Building Envelopes and Air Barrier Systems, ASTM International, West Conshohocken, PA 91.120.99, 2017.

[9] C. Lerma, E. Barreira, R.M. Almeida, A discussion concerning active infrared thermography in the evaluation of buildings air infiltration, Energy and Buildings 168 
(2018) 56-66. https://doi.org/10.1016/j.enbuild.2018.02.050.

[10] E. Barreira, R.M. Almeida, M. Moreira, An infrared thermography passive approach to assess the effect of leakage points in buildings, Energy and Buildings 140 (2017) 224-235. https://doi.org/10.1016/j.enbuild.2017.02.009.

[11] C.J. Ghazi, J.S. Marshall, A CO2 tracer-gas method for local air leakage detection and characterization, Flow Measurement and Instrumentation 38 (2014) 72-81. https://doi.org/10.1016/j.flowmeasinst.2014.05.015.

[12] Y.L. Chen, J. Wen, Estimating a Building Airflow Network using CO2 Measurements from a Distributed Sensor Network, in: Proceedings of the International High Performance Buildings Conference, Purdue, 2010.

[13] J.M. Hart, A practical guide to infra-red thermography for building surveys, Building Research Establishment, Watford, 1992.

[14] P. Wahlgren, E. Sikander, Methods and Materials for an Airtight Building, ASHRAE Transactions 116 (2010).

[15] D.N. Keast, Acoustic Location of Infiltration Openings in Buildings: Final Report, New York, 1978.

[16] D.N. Keast, P. Hsien-Sheng, The Use of Sound to Locate Infiltration Openings in Buildings, in: Proceedings of the ASHRAE/DOE Conference "Thermal performance of the exterior envelopes of buildings", Florida, 1979.

[17] R. Muehleisen, K. Chelliah, SonicLQ: An acoustic method for locating and sizing air leaks in building envelopes, in: INTER-NOISE and NOISE-CON Congress and Conference Proceedings, Chicago, Illinois, Institute of Noise Control Engineering, 2018, pp. 663-669.

[18] K. Chelliah, G. Raman, R.T. Muehleisen, An experimental comparison of various methods 
of nearfield acoustic holography, Journal of Sound and Vibration 403 (2017) 21-37. https://doi.org/10.1016/j.jsv.2017.05.015.

[19] G. Raman, K. Chelliah, M. Prakash, R.T. Muehleisen, Detection and quantification of building air infiltration using remote acoustic methods, in: Proceedings of 43rd International Congress on Noise Control Engineering, Melbourne, 2014.

[20] G. Raman, M. Prakash, R. Ramachandran, H. Patel, K. Chelliah, Remote Detection of Building Air Infiltration Using a Compact Microphone Array and Advanced Beamforming Methods, in: Proceedings - BeBeC, 5th Berlin Beamforming Conference, Berlin, Berlin, 2014.

[21] S. Dudić, I. Ignjatović, D. Šešlija, V. Blagojević, M. Stojiljković, Leakage quantification of compressed air using ultrasound and infrared thermography, Measurement 45 (2012) 1689_1694. https://doi.org/10.1016/j.measurement.2012.04.019.

[22] M.H.F. de Salis, N.V. Movchan, D.J. Oldham, Characterizing holes in duct walls using resonance frequencies, The Journal of the Acoustical Society of America 111 (2002) 25832593. https://doi.org/10.1121/1.1470506.

[23] D.J. Oldham, J. Kang, M.W. Brocklesby, Modelling the Acoustical and Airflow Performance of Simple Lined Ventilation Apertures, Building Acoustics 12 (2005) 277292. https://doi.org/10.1260/135101005775219139.

[24] B. Kölsch, B. Schiricke, J. Estevam Schmiedt, B. Hoffschmidt, Estimation of Air Leakage Sizes in Building Envelope using High-Frequency Acoustic Impulse Response Technique, in: Proceedings of the 40th AIVC Conference, Ghent, Belgium, 2019, pp. 80-89.

[25] M. Ringger, P. Hartmann, Evaluation of an Acoustical Method for Detecting Air Leaks, Air Infiltration Review 11 (1989) 6-9. 
[26] T. Sonoda, F. Peterson, A sonic method for building air-leakage measurements, Applied Energy 22 (1986) 205-224. https://doi.org/10.1016/0306-2619(86)90003-6.

[27] O.A. Hassan, An alternative method for evaluating the air tightness of building components, Building and Environment 67 (2013) 82-86. https://doi.org/10.1016/j.buildenv.2013.05.007.

[28] K. Varshney, J.E. Rosa, I. Shapiro, D. Scott, Air-infiltration measurements in buildings using sound transmission loss through small apertures, International journal of green energy 10 (2013) 482-493.

[29] U. Berardi, S. Pouyan, Exploring acoustical approaches for pre-screening the airtightness of building enclosures, in: 177th Meeting of the Acoustical Society of America, Louisville, Kentucky, ASA, 2019.

[30] V. Iordache, T. Catalina, Acoustic approach for building air permeability estimation, Building and Environment 57 (2012) 18-27. https://doi.org/10.1016/j.buildenv.2012.04.008.

[31] R.W. Graham, Infrasonic Impedance Measurements of Buildings for Air Leakage Determination. Master Thesis, Syracuse, NY, 1977.

[32] N. Bader, P. Holstein, K. Eckert, H.-J. Münch, L. Holtkamp, T.d. van Eschut, Akustisches Verfahren zur Dichtheitsprüfung, in: B. Weller, S. Horn (Eds.), Denkmal und Energie 2018, Springer Fachmedien Wiesbaden, Wiesbaden, 2017, pp. 285-295.

[33] P. Holstein, N. Bader, S. Moeck, H.-J. Münch, D. Döbler, A. Jahnke, Akustische Verfahren zur Ermittlung der Luftdichtheit von Bestandsgebäuden, in: B. Weller, L. Scheuring (Eds.), Denkmal und Energie 2020, Springer Fachmedien Wiesbaden, Wiesbaden, 2020, pp. 111123.

[34] P. Holstein, A. Raabe, N. Bader, A. Tharandt, M. Barth, H.-J. Münch, Energetische Probleme und akustische Verfahren, in: B. Weller, S. Horn (Eds.), Denkmal und Energie 
2017, Springer Fachmedien Wiesbaden, Wiesbaden, 2017, pp. 189-199.

[35] B. Kölsch, A. Tiddens, J. Estevam Schmiedt, B. Schiricke, B. Hoffschmidt, Detection of Air Leakage in Building Envelopes Using Ultrasound Technology, in: T.A. Weston, K. Nelson, K. Wissink (Eds.), Whole building air leakage: Testing and building performance impacts, ASTM International, West Conshohocken, PA, 2019, pp. 160-183.

[36] P. Holstein, M. Barth, S. zur Horst-Meyer, J. Feierabend, Dicht oder undicht - das ist die Frage. Frei nach Shakespeare - Dichtheitsbewertung mit Ultraschall, in: Proceedings of the DACH Jahrestagung, Salzburg, 2015.

[37] J. Estevam Schmiedt, D. Cerra, D. Dahlke, S. Dill, N. Ge, J. Göttsche, A. Haas, U. Heiden, M. Israel, F. Kurz, M. Linkiewicz, D. Patel, M. Peichl, S. Plattner, S. Pless, B. Schiricke, C. Schorn, A. Tiddens, X. Zhu, Remote sensing techniques for building models and energy performance studies of buildings, in: Proccedings of the first Annex 71 Meeting, Loughborough, UK, 2017.

[38] P. Gorzalka, J. Estevam Schmiedt, D. Frommholz, M. Linkiewicz, S. Plattner, C. Schorn, J. Göttsche, B. Hoffschmidt, Remote Sensing For Building Energy Simulation Input - A Field Trial, in: Proccedings of IBPSA Building Simulation Conference, Rome, Italy, 2019.

[39] M. Reader-Harris, Orifice Plates and Venturi Tubes, Springer International Publishing, Cham, 2015.

[40] I.S. Walker, D.J. Wilson, M.H. Sherman, A comparison of the power law to quadratic formulations for air infiltration calculations, Energy and Buildings 27 (1998) 293-299. https://doi.org/10.1016/S0378-7788(97)00047-9.

[41] M.H. Sherman, W.R. Chan, Building Air Tightness: Research and Practice, in: M. Santamouris, P. Wouters (Eds.), Building Ventilation: The State of the Art, Earthscan, 
London, 2006, pp. 137-162.

[42] I.S. Walker, M.H. Sherman, J. Joh, W.R. Chan, Applying Large Datasets to Developing a Better Understanding of Air Leakage Measurement in Homes, International Journal of Ventilation 11 (2013) 323-338. https://doi.org/10.1080/14733315.2013.11683991.

[43] DIN EN, 12114:2000, Thermal performance of buildings - Air permeability of building components and building elements - Laboratory test method, Beuth Verlag GmbH, Berlin 91.060.10, 2000.

[44] C.E. Shannon, Communication in the presence of noise, Proceedings of the IRE 37 (1949) $10-21$.

[45] W.J. Witteman, Detection and Signal Processing, first ed., Springer Berlin Heidelberg, Berlin, Heidelberg, 2006.

[46] F.C. Tenoudji, Analog and Digital Signal Analysis: From Basics to Applications, first ed., Springer International Publishing, 2016.

[47] C. Vornanen-Winqvist, K. Järvi, S. Toomla, K. Ahmed, M.A. Andersson, R. Mikkola, T. Marik, L. Kredics, H. Salonen, J. Kurnitski, Ventilation Positive Pressure Intervention Effect on Indoor Air Quality in a School Building with Moisture Problems, Int. J. Environ. Res. Public Health 15 (2018). https://doi.org/10.3390/ijerph15020230.

[48] L.C. Ng, A. Musser, A.K. Persily, S.J. Emmerich, Multizone airflow models for calculating infiltration rates in commercial reference buildings, Energy and Buildings 58 (2013) 11-18. https://doi.org/10.1016/j.enbuild.2012.11.035.

[49] Afnor, FD P50-784:2016-07-20 Thermal performance of buildings - Implementation guide for NF EN ISO 9972, 2016. 